\title{
The Modest, or Quantificational, Account of Truth
}

\author{
Wolfgang Künne \\ Department of Philosophy, University of Hamburg
}

Truth is a stable, epistemically unconstrained property of propositions, and the concept of truth admits of a non-reductive explanation: that, in a nutshell, is the view for which I argued in Conceptions of Truth. In this paper I try to explain that explanation in a more detailed and, hopefully, more perspicuous way than I did in Ch. 6.2 of the book and to defend its use of sentential quantification against some of the criticisms it has has come in for.

Keywords: truth, non-nominal quantification

\section{Introduction}

All classical object-based correspondence theories are inspired by Aristotle, and they share a difficulty. It arises from a Procrustean structural presumption concerning truth-value bearers, the presumption that all truthcandidates ascribe a property to one or several objects. One can try to avoid this difficulty by applying the Tarskian strategy of recursion. But this strategy, too, works only for languages with a tightly circumscribed structure, and there are long-standing questions as to whether every truth candidate has the kind of structure Tarski's strategy requires. So one should rather try to avoid the difficulty by explaining the concept of truth in such a way that the internal structure of the truth-value bearers is left entirely open. This is the way the difficulty is avoided by truth-theoretical nihilists, since they try to explain this concept without assuming that there are any truth-value bearers at all, and, less ironically, by Moore's fact-based correspondence theory, and by disquotationalism. I have dubbed the conception of truth that I favour and that I shall explain in today's lecture ${ }^{1}$ the Modest Account. 'Quan-

Corresponding author's address: Wolfgang Künne, Eichengrund 30, D-22589 Hamburg, Germany. Email: wolfgang.kuenne@uni-hamburg.de.

1 This paper is based on a manuscript I used for the first Gottlob Frege Lectures given in Tartu in February 2007. The book that I keep on quoting from and referring to is Conceptions of Truth, Oxford 2003 (henceforth: CT). 
tificational Account', or better still, 'Quantificational-Conjunctive Account' would have been more telling names, even if not very graceful ones, and they would not have carried the unpleasant suggestion that one's opponents suffer from the vice of immodesty. It takes truth to be a property of propositions. Like the theories just mentioned it puts no constraints on the internal structure of truth candidates, but arguably it does not run afoul of the problems which plague those theories. By taking the concept of truth not to be explanation-resistant, it opposes Propositional Primitivism, the position of Frege, on the one hand, and early Moore and Russell on the other. So far the Modest Account shares all the features I have ascribed to it with Paul Horwich's Minimalism, but it contrasts starkly with Minimalism in that it assumes that one can finitely state what propositional truth is.

\section{Introducing the Modest Account (I)}

All philosophers, I dare say, would most cordially agree that what you say or think is true if and only if things are as you say or think they are. Aquinas, for example, appeals to this common understanding of 'true' when he maintains: if what the intellect says is true then 'things are as the intellect says (ita [est] in re sicut intellectus dicit).'. William of Ockham maintained that a proposition's being true consists in things being as the proposition says they are (propositionem esse veram est ita esse sicut significatur per propositionem). ${ }^{3}$ Bolzano articulates the same pre-theoretical understanding when he remarks, "In our ordinary transactions it is very common indeed to use the phrases 'That is true' and 'Things are as they are said to be (es ist so, wie es ausgesagt wird)' as interchangeable" (WL, I, 124). Wittgenstein writes in the same vein:

(Wittgenstein) Was er sagt, ist wahr $=$ Es verhält sich so, wie er sagt. What he says is true $=$ Things are as he says. (Wittgenstein 1974,123 )

Presumably we may add, 'What she thinks is true = Things are as she thinks they are.' My last witness is Strawson: ${ }^{4}$

(Strawson 1) A statement is true if and only if things are as one who makes that statement thereby states them to be. A belief

2 From (Aquinas 1975) quoted in Ch. 5.3.1.

3 Expositio in librum Perihermeneias Aristotelis, prooemium (penultimate sentence), (Ockham 1974-1988, II, 377).

${ }^{4}$ Cf. also (Strawson 1971a, 226-227), (Strawson 1980, 326-326) and (Strawson 1992, 51, 8591) as well as (Mackie 1973, 22, 50, 53, 57), (Rundle 1979, 363-364, 375) and (Sainsbury 2001, 105). 
is true if and only if things are as one who holds that belief thereby holds them to be. (Strawson 1976, 273)

I must confess that I like the German way of putting it better, for 'es ist so' and 'es verhält sich so' do not contain a noun like 'things' which might be taken to impose a certain predicative structure on the truth candidate. But I hasten to add that the English way of putting it is really equivalent, for if you correctly state that it is snowing, you can be said to have stated "how things are", even though no thing is having anything predicated of it.

For most philosophers such truisms about truth are only a preparatory step on their way towards more demanding accounts of truth. I propose to take the alleged stepping-stone as a firm resting place. (I think this was Wittgenstein's position, too, and I am certain that it actually is Strawson's view.)

Now, as it stands, the quotation from Strawson gives us two accounts, one for statements and one for beliefs. This duality should be avoided if possible, since a pair of explanations seems to offer both too little and too much. It seems to offer too much because 'true' as applied to statements and 'true' as applied to beliefs appears to be univocal. (The sentence 'His opinion was as true as her assertion' is not a zeugma: it does not, as it were, force one word into two conflicting services, as is done with the verb in Alexander Pope's 'She sometimes counsel took and sometimes tea.) In another respect a pair certainly does not offer enough, because not all truths are contents of statings or believings.

\section{What Is It that Is True or False?}

At least prima facie we ascribe truth and falsity to a motley multitude of entities such as allegations, beliefs, conjectures, contentions, judgements, reports, statements, suppositions, thoughts, and so on. But perhaps this appearance of multiplicity is deceptive.

Consider beliefs and statements. If we say 'Ben's belief that one day all the dead will rise is due to childhood indoctrination, whereas Ann's belief that one day all the dead will rise is the result of adult conversion', we do not ascribe two different origins to one and the same item. Similarly, if his belief that $p$ is firm whereas her belief that $p$ is easily shaken, there is no one thing that is both firm and easily shaken. In both cases we take beliefs to be identity-dependent on believers. Let us call beliefs, thus understood, 'believings. When Ann changes her mind (with respect to the question whether p) whereas Ben remains obstinate, then only one of the two believings is left. But of course, in another sense of 'belief' Ben and Ann share the belief that $p$, for a while: his long-standing and firm belief (believing) and her more recent, easily shaken and finally lost belief (believing) have the same 
content. The same holds, mutatis mutandis, for statements (Strawson 1971C, 190). When we say 'Ben's statement that $p$ was followed by a startled silence, but only two days later Ann's statement that $p$ was received with thunderous applause', we treat statements as identity-dependent on speakers, i.e. as datable illocutionary acts. But in another sense of 'statement' both speakers made the same statement: his ill-received, and her well-received, speechact have the same content. When we ascribe truth (or falsity) to beliefs and statements we do not ascribe it to believings or statings, but rather to what is believed and what is stated, and that may be something that various believings and statings have in common. What A believes, namely that $p$, is true iff $\mathrm{A}$ is right in believing that $p$. What $\mathrm{B}$ believes, namely that $q$, is false (a falsehood) iff B's believing that $q$ is erroneous (an error). In saying that somebody's belief or statement is true (false) we characterize in one breath, as it were, a believing or stating and its content.

Of course, not all truths are contents of statings and believings. You might entertain a true thought without belief, and you might formulate a truth in the antecedent of a conditional although you do not assert the antecedent (Strawson 1971a, 216-220). Furthermore, there are ever so many truths which will never actually become the contents of any speech-act or thought, whatever its psychological or illocutionary mode. (There is a true answer to the question 'How many commas occur in the first edition of the Encyclopaedia Britannica?', but presumably nobody will ever answer it, whether in speech or in thought.) Finally, not all sayings and thinkings have a truth-evaluable content: when you ask yourself or others how often the letter A occurs on this page, the content of your mental or illocutionary act is not a truth-candidate.

At this point the term 'proposition' as used in many philosophical writings promises help. We can introduce this term in the following way. Starting from a thought-ascription or a speech-report of the form

(I) A verb-s that $p$

we first bring it into the format

(II) That $p$ is the content of A's Verb ${ }_{n}$,

where 'Verb ${ }_{n}$ ' is a verbal noun (such as 'belief' or 'statement') corresponding to the verb (e.g. 'believes', 'states') in (I). Then we adorn the clause in (II) with a prefix:

(III) The proposition that $p$ is the content of A's Verb ${ }_{n}$.

And finally we add the caveat that something which could be thought or said in some mode or other may never in fact be thought or said in any 
mode, in which case some proposition would never actually be the content of anyone's verb-ing.-You come to understand the word 'proposition' by learning to accept, as a conceptual matter of course, any inference from (a substitution-instance of) schema (I) via (II) to the corresponding instance of (III), et vice versa, and to acknowledge the possibility mentioned in the caveat.

Following Husserl, I make a point of taking the proposition that $p$ to be the content, rather than the (intentional) object, of a thinker's verb-ing that $p$, and of assigning the latter role to states of affairs.

The list of truth-candidates with which I began this section consisted of verbal nouns. We saw that all of them have readings under which they are used to refer to propositions. Unlike 'proposition' those words for partly overlapping subclasses of propositions (for things believed, things stated, etc.) have no technical philosophical flavour whatsoever. Furthermore, plenty of non-verbal nouns, such as 'axiom', 'dogma', 'tenet', 'thesis' and 'theorem, which also determine partly overlapping subclasses of propositions, are certainly not kept for the special use of philosophers either. Those who are keen to ban talk of propositions often seem not to realize how many general terms which are common coin in non-philosophical discourse do 'specialized' duty for 'proposition'.

\section{Introducing the Modest Account (II)}

Let us return to the truism about truth I am trying to spell out. Suppose Ann says or thinks, in some illocutionary or psychological mode or other, that it is almost dawn, and what she says or thinks, the propositional content of her saying or thinking, is true. Then things (really) are as she says or thinks they are. One senses a certain air of correspondence when one stares at the little word ' $a s$ ' in this formulation (or at 'ov $\tau \omega \varsigma-\omega \varsigma$ ', 'ita-sicut' and 'so-wie' in the corresponding Greek, Latin and German locutions). ${ }^{5}$ In order to see what this trace of correspondence amounts to (how little it amounts to), let us focus on that two-letter word for a moment. From the premiss

(1) Ann thinks that it's almost dawn, and it is almost dawn

we can conclude

(2) Things (really) are as Ann thinks they are.

In (1) the point of the word 'as' in (2) is captured by a conjunction, more exactly: by the interplay between the second conjunct and the specification of the content of Ann's thinking in the first conjunct by means of the same

5 Kahn has the same impression (Kahn 1973, 336). 
sentence taken in the same sense. Can we reformulate the conclusion (2) in manner that preserves the conjunctive structure of the premiss (1)? If we try it along the following lines:

(?) Ann thinks something, and it

we see that this requires completion by the truth-predicate:

(3) Ann thinks something, and it is true.

But this is not what we want when we are intent on elucidating truth talk. In (3) we quantify into the position of the that-clause in (1), hence into the position of a singular term. We have parsed the premiss for our existential generalization in this way:

(1a) Ann thinks (that it's almost dawn), and it is almost dawn.

What we need is rather a quantification into the position of what follows the complementizer 'that', quantification into the position of a sentence. The complementizer would have to survive such a quantification, for now we are meant to parse the premiss differently:

(1b) Ann thinks that (it's almost dawn), and it is almost dawn

Do we have this type of quantification in our language? I think we do:

(4) Ann thinks that things are a certain way, and things are that way.

My formulation of the modest conception of truth draws upon this observation:

$\left(\operatorname{Mod}^{*}\right) \forall x(x$ is true $\Leftrightarrow x$ is the proposition that things are a certain way, and things are that way ).

Let us reflect on the role the sentence after 'and' is playing here by contrasting it with another role it can play. The word 'them' in 'Ben admires Bacon's paintings, whereas Ann detests them' is a pronoun of laziness (that can be replaced by its nominal antecedent 'Bacon's paintings'). Similarly, the sentence 'things are that way' in a context like

(5) Most students make fun of Professor N.N. and some even hate him, but the dean does not know that things are that way.

is a prosentence of laziness (that can be replaced by its sentential antecedent, i.e. the conjunction which precedes 'but'). Note that it is not the phrase 'that way' which functions anaphorically in (5), but the sentence 'things are that way' as a whole. The phrase by itself functions anaphorically in a context like 
(6) Ann moves gracefully, but Ben does not move that way.

Here it is a proadverb of laziness that can be replaced by its adverbial antecedent, whereas in (5) the phrase 'that way' is only a syncategorematic part of a prosentence.

Now proforms of laziness are to be distinguished from quantificational proforms. The word 'it' in 'Ann is fond of something, and Ben is also fond of it' is a quantificational pronoun. Similarly, the sentence 'things are that way' in (4) is a quantificational prosentence, and that's what it also is in $\left(\mathrm{MOD}^{*}\right)$.

In his Philosophical Investigations Wittgenstein points out that 'Es verhält sich so' can be regarded as the colloquial counterpart to a sentential variable in a formal language (Wittgenstein 1967, \$134). ${ }^{6}$ Using a few symbols from the (Polish) logicians' toolbox we obtain a rendering of the modest conception that is less cumbersome than $\left(\mathrm{MOD}^{*}\right)$ :

(MOD) $\forall x(x$ is true $\Leftrightarrow \exists p(x=$ the proposition that $p . \&$. $p))$

I hope that the above way of explaining (MOD) via (4) and (MOD*) carries more conviction than my earlier attempt which employed the strange quantifier phrase 'For some way things may be said to be,...' $(C T, 326)$. Most reviewers of the book, though in general extremely kind to its author, have found my use of this phrase rather confusing, and they were right. To some, it looked like quantification over ways: thus Mario Gómez-Torrente (2005), Adolf Rami (2005), and Thomas Hofweber (2006). To others, it looked like quantification over states of affairs: thus Geert Keil (2005) and Marian David (2005). Diego Marconi (2006) was not very happy with it either; and Tobias Rosefeldt (2005) discreetly improved upon it.

$\left(\mathrm{MOD}^{*}\right)$ and $(\mathrm{MOD})$ are notational variants of one and the same minimal definition of (propositional) truth. The prologue 'the proposition that' (' ] ]', for short) functions as a singular-term forming operator on sentences. A substitution-instance of the open sentence ' $(x=[p] \& p)$ ' would be 'Goldbach's Conjecture $=$ the proposition that each even number greater than 2 is the sum of two primes'. An identity claim of the form ' $x=$ the proposition that $p$ ' holds just in case the following condition is fulfilled: anyone whose utterance was to express $x$ would thereby be saying that $p$, and anyone who was to say that $p$ would thereby make an utterance which expresses $x$.

Unlike Correspondence conceptions of truth the modest account makes no use of a two-place predicate signifying a relation between a truth-value bearer, or a part of it, and something else (whether an object, a fact or an event). After all, in $\left(\mathrm{MOD}^{*}\right)$ and (MOD) the point of the 'as' in 'Things are

${ }^{6}$ Prior emphasized the philosophical fecundity of this passage in (Prior 1967, 229) and (Prior 1971, 38) (henceforth $O T$ ). 
as they are said or thought to be' is captured by a connective rather than a twoplace predicate. In 1929 Tadeusz Kotarbinski, Tarski's philosophy teacher in Warsaw, tried to explain what he called the classical conception of truth. According to that conception, he said, Jan thinks truly if and only if he thinks in agreement with reality. Kotarbinski did not only explicitly reject a pictorialist account of 'agreement with reality', he implicitly rejected all relational readings of the classical formula. In his interpretation of that formula no trace of a two-place predicate is left: 'Jan thinks truly', Kotarbinski says, 'if and only if Jan thinks that things are thus and so, and things are indeed thus and so. Obviously this is very close to the spirit of (MOD), so Kotarbinski is one of the heroes in my book $(C T, 343-346)$.

The modest account tries to tell us what all true propositions have in common. In taking truth to be a property it does not deny that it is a very peculiar property indeed. It is the one and only property of any proposition to the effect that things are thus-and-so which allows us to infer directly that things really are thus. Truth is unique among all the properties propositions may have in being, so to speak, by itself transparent, enabling us to look through the proposition right to the (non-propositional) world. ${ }^{7}$ Note that the modifiers 'directly' and 'by itself' are needed to shield off apparent counter-examples which would otherwise be real counter-examples. Here is a list of properties of the proposition that the moon is round which also allow us to infer how things stand with the moon:

being such that anyone who were to believe it would be right in so believing,

being held true by an omniscient God, if there is any such entity,

being deducible from truths,

being true and referred to in this lecture.

Obviously all these properties are truth-entailing, in the sense that if a proposition has any of them it follows that it is a true proposition. They owe their transparency to the property of being true. The latter is the only property of propositions which is transparent in its own right. One can, and should, acknowledge the uniqueness of the property of being true rather than go to the nihilists' extreme of denying its propertyhood.

In trying to say what all true propositions have in common the modest account differs markedly from Horwich's minimalism, for the latter refrains

7 Several paintings by René Magritte, such as La Condition humaine, can be seen to illustrate this. 
from offering any principle of the form, ${ }^{\prime} \forall x(x \text { is true iff ... } x \ldots)^{, 8}$ Moreover, whereas Horwich's "minimal theory" is conceptually extremely corpulent, the modest account is conceptually very slim. Seen in the light of (MOD) the modest account explains 'true' in terms of a few logical operators (and the concept of a proposition). Thus it appears reasonable to call truth a broadly logical property.9 (Only "broadly logical", because the concept of a proposition is not a logical concept.) Furthermore, Horwich's "minimal theory" had to be supplemented by the axiom that only propositions are true. By contrast, (MOD) ensures this by itself, in virtue of the component ${ }^{`} \exists p(x=$ $[p])^{\prime 10}$

\section{A Brief Sermon on 'Deflationism'}

Is my account of truth deflationary? In my book I refrained from affixing this label to any conception of truth, because I found a depressingly confusing multiplicity of usages in the literature. ${ }^{11}$ According to Hartry Field, "Deflationism' is the view that truth is at bottom disquotational" (Field 2001, 405). This implies that deflationists must take truth to be a property of something one can put between quotation-marks. But then Paul Horwich's minimalism cannot be called deflationist, since he takes truth to be a property of propositions. Yet he is very keen to promote his conception of truth under the label 'deflationism'. Truth-theoretical nihilists like Strawson in 1949, Christopher Williams and Dorothy Grover would also loose the right to call them-

8 See (CT, subsect. 6.1.1), (Horwich 1998, 20, 33, 111), (Defense, 560).

9 If the modest account is taken as a reductive (dismantling) analysis rather than as a "connecting analysis" or elucidation which explains a concept by showing its connections with other concepts [see (CT, Ch. 1, sub (LAMBERT))], one has to face the charge of vicious circularity here. The charge could be deflected by assuming that the meaning of ' $\&$ ', for example, is not given by truth-tables, but rather by a natural deduction system, or by an axiomatic system, which codifies the role this connective plays in the context of inference. When Tarski heard rumours about his theory being circular he gave a reply along the same lines: see (CT, Ch. 4.1.3) above, on (Df. 2), and the reference given there.

${ }^{10}$ As was pointed out in a long fn to $(C T$, subsect. 6.1.1) above, the explanation of universal generalizations about truth causes grave problems for minimalism. Since (MOD), unlike MT, is itself a universal generalization, the generality of general facts about truth causes no problems for the modest account.

${ }^{11}$ Isaiah Berlin's paper 'Logical Translation' (1980) contains what is perhaps the earliest philosophical use of this pair of terms. Berlin used them ("for want of a better label") to characterize opposite vices in metaphysics, ontological stinginess (of the logical positivist type) and ontological prodigality (of the Meinongian type): "deflationists" condemn much that is significant as nonsensical because their ontology admits too few entities; "inflationists", on the other hand, accept as significant much that is nonsensical because their ontology admits too many entities. When Cartwright borrowed Berlin's terms a decade later in (Cartwright 1987a), he also used them for labelling two ontological positions which he deemed to be equally unacceptable. Cf. also (Cartwright 1987b, 225-226). 
selves deflationists, ${ }^{12}$ since they deny that truth is a property at all.-Marian David links deflationism with metaphysical distaste for non-physical entities (David 1994, 53-60). Again minimalism is out, and so is every conception according to which truth is a property of type-sentences.-According to Paul Boghossian, Crispin Wright and William Alston, deflationism is the view that "it is a mistake to suppose that there is a property of truth (falsity) that one attributes to propositions, statements, beliefs, and/or sentences."13 Once again minimalism turns out to be inflationist, and so does disquotationalism, because they take truth to be a property of propositions or of certain linguistic objects.-A few pages later Wright tells us that it is deflationism's "most basic and distinctive contention that 'true' is merely a device for endorsing assertions" (T\&O, 33, cp. 21) ${ }^{14}$ But this characterization fits only the position Strawson took in 1949.-Horwich himself seems to mean by 'deflationism' the denial of the claim that "the property of truth has some sort of underlying nature" (Horwich 1998, 120), but why not call the minimalist account an attempt at disclosing the nature of truth?

In a review of my book (and in some other papers) Douglas Patterson has recently specified a disjunctive sufficient condition of being deflationary. He stipulates that an account of truth is deflationary

if it, in conjunction with minimal additional resources such as information about the standard names of sentences, implies all instances of the schema " $x$ is true if and only $p$ " where the sentence substituted for " $p$ " shares its meaning with $x$, or, where $x$ is a proposition, the proposition expressed by the sentence substituted for " $p$ " is $x$.

On the basis of the second disjunct he classifies me as a deflationist. Note that this disjunct needs a similar rider as the first one. The biconditional 'Logicism is true iff arithmetic is a branch of logic' is an instance of the schema

(T) $x$ is true iff $p$,

and the proposition referred to in its left branch is the proposition expressed by its right branch. But nobody would expect an account of truth to imply this biconditional. So names of propositions do not seem to be "standard names.' But if we replace 'Logicism' by 'That arithmetic is a branch of logic', we seem to have hit upon a "standard name." Generally, if truth is ascribed to

${ }^{12}$ Claimed by Grover in Ch. 9 of her collection (Grover et al. 1992).

${ }^{13}$ See (Boghossian 1990, 161), (Wright 1992, 16) (hereinafter TઐO). A few pages later Wright acknowledges that at least one "deflationist" does take truth to be a property $(T \mho O, 21, \mathrm{fn}$. 15). The quotation is from (Alston 1996, 41, cp. 2) (henceforth RCT). In (Kirkham 1992, $307 \mathrm{ff}$ ) (ThT) "the Deflationary Thesis" is explained along the same lines.

${ }^{14}$ Somewhat ironically, Wright's justified complaint that "deflationism is actually something of a potpourri" $(30)$ is confirmed by the use of this term in $T \lessdot O$. 
propositions rather than to sentences, the relevant instances of $(\mathrm{T})$ are also instances of the Denominalization Schema

(Den) That $p$ is true iff $p$.

Let me replace the misleading term 'standard name' by a bit of my own jargon. The designator in the left branch of (Den) is a revealing designator $(C T$, 74-75, 184-185). A designator of an expression is revealing iff somebody who understands it can read off from it which (orthographically individuated) expression it designates. Standard quotational designators, such as 'Yahveh', and the designators which Tarski calls structurally descriptive names, like 'the word which consists of the Hebrew letters Yod, Hay, Vav and Hay (in this order)', are revealing designators in my sense, whereas 'the holy and ineffable name of God in the Hebrew Bible' is not. Similarly, a designator of a proposition is revealing iff somebody who understands it (and who knows what its context-sensitive components designate in a given context $c$ ) thereby knows which proposition it designates (in $c$ ). That-clauses are revealing designators of propositions, whereas names like 'Logicism' and definite descriptions like 'Frege's most famous thesis in the philosophy of mathematics' are not.

Patterson is certainly right in saying that the second disjunct of his stipulation (when the requisite rider has been added) makes me come out as a deflationist, for I do even go out of my way, as he puts it, to prove that (MOD) implies the instances. I see no reason to complain, for I do not take this label, as partially explained by Patterson, to be an insult. But then, the first disjunct of his stipulation makes Tarski come out as a deflationist, and many people who employ this epithet would object to this classification. To be sure, Tarski's criterion of material adequacy for definitions of truth-predicates is beloved by every philosopher who takes pride in calling himself deflationist, but most of them ${ }^{15}$-as well as their opponents ${ }^{16}$ - would object that the recursive machinery which is put to work in Tarskian definitions of truthpredicates for languages that are not codes $(C T, 194-200)$ excludes them from the honour, or the shame, of being deflationary. So I still think that in view of this terminological chaos we should put the term 'deflationism' on Otto Neurath's Index Verborum Prohibitorum.

\section{Material Adequacy and Partial Definitions}

In his 1910-11 lectures in London G.E. Moore noted a constraint on definitions of truth:

\footnotetext{
${ }^{15}$ Paul Horwich, for example: see his (Horwich 2003).

${ }^{16}$ Donald Davidson, for example: see his (Davidson 1996, 269-270). Interestingly critics of deflationism seldom confess to being inflationists.
} 
(Moore) Suppose that ...my friend believes that I have gone away for my holidays. There is, I think, no doubt whatever that there is at least one ordinary sense of the word 'true' ..., such that the following statements hold: if this belief of his is true then I must have gone away for my holidays;.. and, conversely,... if I have gone away, then this belief of his certainly is true... In other words, my having actually gone away for my holidays is both a necessary and a sufficient condition for the truth of his belief... If, therefore, we are to find a correct definition of ...'true' it must be a definition which does not conflict with the statement that these conditions are necessary and sufficient conditions. (Moore 1953, 274-275)

This is a sadly neglected (propositionalist) precursor of Tarski's famous Criterion T. ${ }^{17}$ The that-clause in 'the belief that $p$ ' specifies what it takes for the belief to be true: Nothing more is required for its truth, and nothing less will suffice. Surely a good way to demonstrate the absence of a conflict between statements of the form

(Den) The proposition that $p$ is true if and only if $p$

and (MOD) would be to show that (MOD) enables us to derive instances of (Den). Using ' $\mathrm{S}$ ' as abbreviation of the sentence 'Snow is white', our task is to derive

$\left(\right.$ Den $\left._{1}\right)[S]$ is true $\Leftrightarrow S$.

In order to derive the left-to-right half we need the following inference rule:

$$
\begin{aligned}
& \left(=E_{\text {Elim. }}\right)^{*} \quad \Gamma: \quad[A]=[B] \quad \Gamma: \quad[A]=[B] \\
& \begin{array}{llll}
\Delta: & A & \Delta: & B \\
\cline { 1 - 2 } \Gamma, \Delta: & B & \Gamma, \Delta: & A
\end{array}
\end{aligned}
$$

This rule is very plausible indeed. After all, we are ready to accept arguments like

(P1) The proposition that Prague and Cracow are similar = the proposition that Cracow and Prague are similar.

( $\left.\mathrm{P}_{2}\right)$ Prague and Cracow are similar.

${ }^{17}$ See (CT, Ch. 4). Cf. Also Ramsey (1991, 14): "[A] belief that $\mathrm{p}$ is true if and only if $\mathrm{p}$. We may deride this as trivial formalism, but since we cannot contradict it without absurdity, it provides a slight check on any deeper investigations that they must square with this obvious truism". So, pace Anil Gupta $(1998,265)$ and many others, Tarski was not the first to use such an equivalence as a touchstone for explanations of 'true'. 
(C) So, Cracow and Prague are similar.

as intuitively valid. Here is the proof of $[S]$ is true $\rightarrow S$ :

$\begin{array}{lllll}1 & (1) & {[\mathrm{S}] \text { is true }} & & \text { Assumption } \\ 1 & (2) & \exists p([S]=[p] \& p) & 1 & \text { Df. (MOD) } \\ 3 & (3) & {[\mathrm{S}]=[\mathrm{T}] \& \mathrm{~T}} & & \text { Ass. (for } \exists \text { Elim.) } \\ 3 & (4) & {[\mathrm{S}]=[\mathrm{T}]} & 3 & \text { \& Elimination } \\ 3 & (5) & \mathrm{T} & 3 & \text { \& Elimination } \\ 3 & (6) & \mathrm{S} & 4,5 & (=\text { Elimination) } \\ 1 & (7) & \mathrm{S} & 2,3,6 & \exists \text { Elimination } \\ & (8) & {[\mathrm{S}] \text { is true } \rightarrow \mathrm{S}} & 1,7 & \rightarrow \text { Introduction }\end{array}$

Here is the derivation of the right-to-left half of $\left(\operatorname{Den}_{1}\right)$ :

$1 \quad(1) \quad S$

(2) $[S]=[S]$

(3) $[\mathrm{S}]=[\mathrm{S}] \& \mathrm{~S}$

(4) $\exists p([S]=[p] \& p)$

(5) $[\mathrm{S}]$ is true

(6) $\mathrm{S} \rightarrow[\mathrm{S}]$ is true
Assumption

$=$ Introduction

1,2 \& Introduction

$3 \quad \exists$ Introduction

4 Df. (MOD)

$1,5 \rightarrow$ Introduction

By presenting these proofs I do not want to contradict Horwich's claim that $\left(\right.$ Den $\left._{1}\right)$ does not stand in need of a proof. He is right, it does not. (This is not to deny that $\left(\operatorname{Den}_{1}\right)$ is derivable from true premisses. Every truth is; e.g. from itself, or from its conjunction with another truth.) But the fact that not only $\left(\right.$ Den $\left._{1}\right)$ but, along the very same lines, all the other "axioms" of the "minimal theory" can be proved by appealing to (MOD) and some logical rules of inference shows, I think, that (MOD) is more fundamental than those "axioms." At this point one might even wonder whether the propositions that make up MT really are axioms. "Traditionally", Frege rightly says, "what is called an axiom is a thought whose truth is certain without, however, being provable by a chain of logical inference" (Frege 1967b, 319). ${ }^{18}$ Here is a comparison (drawn from Leibniz): we are ready to accept ' $2+2=4$ ' as a matter of course, without supporting argument,-failure to accept this equation

${ }^{18}$ An axiom, Leibniz says, is "neither capable of being proved nor in need of it (n'est point capable d'estre prouvé et n'en a point besoin)" (Leibniz 1962, Bk. IV, Ch. 9, sect. 2, 434). In $\$_{3}$ of Die Grundlagen der Arithmetik Frege echoes this when he characterizes axioms as truths which are "neither capable, nor in need of, being proved (eines Beweises weder fähig noch bedürftig)." For a thorough discussion of Frege's indebtedness to, and development of, the Euclidean rationalist tradition see (Burge 1998). In (CT, Ch. 7.1.1) we will hear Brentano's echo of Leibniz. 
would count as manifestation of deficient understanding. But for all that, ' 2 $+2=4^{\prime}$ is provable. ${ }^{19}$

Why do I go out of my way to show that instances of the Denominalization Schema are derivable from (MOD)? Patterson's answer to this question reveals a serious misunderstanding of my position: "Künne", he argues, engages in that derivational activity, "since he accepts ... that a theory's [implying those instances] is a necessary condition of adequacy." First of all, I do not accept this necessity claim (nor do I endorse the corresponding sufficiency claim), and secondly, my real motive was-curiosity.

Quite a few conceptions of truth receive a fair amount of critical attention in $C T$, but in no case do I object to a conception for the reason that it implies neither instances of (Den) nor instances of schema (T) in which truth is ascribed to sentences. At one point I applaud one of Russell's objections to (what he takes to be) William James' account of truth. Russell attributes to James the tenet that it is true that $p$ iff it makes for happiness to believe that $p$. His critique of this contention shows that it is incompatible with both halves of instances of (Den):

(Russell) Take the question whether other people exist... It is plain that it makes for happiness to believe that they exist-for even the greatest misanthropist would not wish to be deprived of the objects of his hate. Hence the belief that other people exist is, pragmatically, a true belief. But if I am troubled by solipsism, the discovery that a belief in the existence of others is 'true' in the pragmatist's sense is not enough to allay my sense of loneliness: the perception that I should profit by rejecting solipsism is not alone sufficient to make me reject it. For what I desire is not that the belief in solipsism should be false in the pragmatic sense, but that other people should in fact exist. And with the pragmatist's meaning of truth, these two do not necessarily go together. The belief in solipsism might be false even if I were the only person .... in the universe. (Russell 1966)

The core of Russell's argument (using ' $p_{1}$ ' as abbreviation for 'There are other people' and ' $p_{2}$ ' for 'I am alone') is this: (A) It may be pragmatically-true that $p_{1}$, although not- $p_{1}$, and (B) it may not be pragmatically-true that $p_{2}$, although $p_{2}$. Hence 'pragmatically-true' is not equivalent with 'true'. Why does this follow? Well, replacing 'pragmatically-true' in the first conjunct

${ }^{19}$ Contrast (Horwich 1998, 50). Horwich himself compares the axioms of MT rather with the Peano axioms for elementary number theory (ibid. 138). But of course, which comparison is more apt is part of the issue. (On proving ' $2+2=4$ ' see (Leibniz 1962, IV, 7, \$10) and the emendation of his proof in (Bolzano 1974, Appendix \$8) and in (Frege 1986, \$6)). 
by 'true', we see that it does not comply with the right-to-left half of (Den), and making the same substitution in the second conjunct, we recognize that it offends against the left-to-right half of (Den). ${ }^{20}$ In praising Russell and Moore for their insistence on compatibility with the pertinent instances of (Den) I do not demand derivability.

I thought it worthwhile to ascertain whether (MOD) implies instances of (Den), because I took their derivability (and I still take it) to count in favour of an account of truth. I also wanted to find out which resources are needed for the derivation. Why are instances of (Den), apart from those that are paradox-inducing, "good things for an account of truth for propositions to be committed to"?, Patterson asks. I reply: Because a declarative sentence can always be used to specify the truth-condition of the proposition it expresses. This answer is not circular, since the concept of what truth-conditions are conditions of is explained by (MOD), not by instances of (Den).

In saying that derivability of instances of (Den) counts in favour of an account of truth I do not claim that it guarantees the material adequacy of an account. Actually, I reject that claim. The minimal definition (MOD) implies, for example, the biconditional

$\left(\right.$ Den $\left._{2}\right)$ That e-mails can be a nuisance is true iff e-mails can be a nuisance.

Should we say of $\left(\operatorname{Den}_{2}\right)$, echoing Tarski's contention about instances of sche$\mathrm{ma}(\mathrm{T})$ in which truth is ascribed to sentences, that it is a partial definition of 'is true', i.e. a definition of 'is true' as applied to the proposition that is designated in the left branch? I argue in CT that we should not. (i) If $\left(\operatorname{Den}_{2}\right)$ were a partial definition of the truth-predicate, it should allow us to eliminate this predicate from all contexts in which it is applied to the proposition that e-mails can be a nuisance. Now if you were to say, 'The proposition that is referred to in the left branch of $\left(\operatorname{Den}_{2}\right)$ is true', you would apply 'is true' to that very proposition. But obviously one cannot remove 'is true' from this context. Since so-called partial definitions allow us to eliminate the truth-predicate only from contexts in which it is preceded by a that-clause, they scarcely deserve the title 'definition'. (Quine raised the same objection against Tarski's claim that his instantiations of schema (T) are partial definitions: see $(C T, 235))$. (ii) If $\left(\mathrm{Den}_{2}\right)$ were a partial definition of 'is true', then somebody who cannot comprehend the proposition that e-mails can be a nuisance cannot fully understand the truth-predicate. If you lack the

\footnotetext{
${ }^{20}$ Whereas Lewis takes 'It is useful to believe that cats purr, iff cats purr' to be "manifestly not a priori", Russell declares 'It is useful to believe that there are other people, iff there are other people' to be manifestly false. Lewis' verdict could be correct even if Russell's is not.
} 
concept of an e-mail you cannot grasp that proposition, but would anyone maintain that our ancestors were unable to understand 'is true' fully because they did not possess the concept of an e-mail? (iii) If instances of (Den) were partial definitions of the predicate 'is true' then its definition would be, as Tarski puts it, "so to speak their logical product." (Tarski 1933, 187). But nobody understands their logical product, for that would require possession of every concept that is expressible in English, whereas quite a few people, I venture to say, understand 'is true' (Künne 2003, 238-241, 359). ${ }^{21}$ Since the logical product of all (not paradox-inducing) instances of (Den), given a suitable infinitary logic, implies each of those instances, I do not take their derivability to be a sufficient condition for adequacy.

\section{Non-Nominal Quantification (I)}

Many philosophers' tend to raise their eyebrows when they look at the second quantifier in

$$
\text { (MOD) } \forall x(x \text { is true } \Leftrightarrow \exists p(\mathrm{x}=[p] \& p)) .
$$

The position that is here quantified into is not that of a name (singular term) but that of a sentence. So what is invoked here is a kind of non-nominal, or higher-order, quantification. I think that non-nominal quantification is ubiquitous in natural languages. From 'Ann and Ben met in the garden [at midnight]' we can infer, 'Ann and Ben met somewhere [somewhen]'. This is quantification into adverbial positions, as the appropriate 'namely' rider shows: 'namely in the garden [at midnight]'. In what follows I shall be concerned with two types of non-nominal quantifications. In this section I shall focus on what is nowadays commonly mislabelled quantification into predicate position.

Let us first brood for a while upon the structure and content of elementary predications. The declarative sentence

(7) Ann is lazy

consists, as philosophers have known for a long time, of a singular term, the name of good old Ann, and a predicate, full-stop. Well, it is not for such a long time that philosophers know this. Before Frege they have kept on saying for many centuries that sentences like (7) consist of three components, a subject, a copula and a predicate. Obviously 'predicate' is used differently in

${ }^{21}$ The sotto voce passage towards the end of $\$ 1$ of Patterson's paper (Patterson 2005) reveals some sympathy with the line of thought in (iii), but since it occurs in an aside on an analogous move in (Gupta 2002), no reader would guess that (iii), under the nickname 'argument from conceptual overloading, figures quite prominently in CT. 
these descriptions of sentential structure. According to the Fregean conception of a predicate, which I endorse, you extract a predicate from a sentence that contains at least one name (singular term) by deleting at least one nameoccurrence. Thus understood, predicates are sentence-forming operators on singular terms, and the copula 'is' is part of some of these operators. Notice that this is a far cry from the claim, upheld by at least one important postFregean philosopher, that the word 'is' occurs in a predicate in the same way as its echo occurs in the word 'Islam', as a fragment of a semantically seamless whole.

In order to avoid terminological confusion I shall shun the old use of the word 'predicate. How then are we to classify the adjective in (7)? Appropriating another entry in the dictionary of traditional logic, I shall call it a general term. The copula, we can now say, is an operator which takes general terms as input and delivers predicates as output.

Even within the realm of elementary predications, a general term may very well be more complex: in 'Ann is a philosopher' it is a phrase consisting of an indefinite article and a noun. Furthermore, as we all know, not every elementary predication contains the copula in the shape of a word like 'is'. After all, when Plato reflected for the first time on the structure of elementary predications his paradigm was 'Theaetetus sits'. But very soon afterwards his greatest pupil tried to uncover a copula even in sentences like 'Theaetetus sits' or

(8) Socrates walks.

I am alluding to Aristotle's notorious constructio periphrastica:

(Aristotle) It makes no difference whether we say of a man that he walks $(\beta \alpha \delta \iota \zeta \epsilon \iota)$, or whether we say that he is walking $(\beta \alpha \delta \iota \zeta \omega v$ $\epsilon \sigma \tau \iota v){ }^{22}$

(We better forget about the English progressive aspect in this context.) Not only the Schoolmen have followed Aristotle's footsteps in this respect:

(Port-Royal) C'est la même chose de dire 'Pierre vit', que dire 'Pierre est vivant' (Arnauld and Nicole 1965, II/2).

(Whately) ['To be'] is the only verb recognised by Logic; inasmuch as all others are compound; being resolvable, by means of the verb

${ }^{22}$ Aristotle, De Interpretatione 12: $21^{b}$ 9-10; cf. Metaphysics V, 7: $1017^{a}$ 27-30; Anal. Pr. I, 46: 51b13-15. 
'to be', and a participle or adjective: e.g. 'the Romans conquered': the word 'conquered' is both copula and predicate, being equivalent to 'were (Cop.) victorious (Pred.).'.23

(Bolzano) Each inflected verb that is different from the word 'is' can be replaced, without any essential change of meaning, by the combination of 'is' with the (present tense) participle derived from that verb. 'A [verb]s' is tantamount to 'A is [verb]ing'. (Jedes bestimmte Zeitwort, das von dem Worte Ist verschieden ist, kann ohne alle wesentliche Veränderung des Sinnes, durch das Wort Ist verbunden mit einem von dem gegebenen Zeitworte abgeleiteten Particip, vertauschet werden. A thut, ist durchaus gleichgeltend mit: A ist thuend.) (WL, II, 10)

But one may very well wonder whether the construction 'is' + participle is really tantamount to the finite form of the full verb, ${ }^{24}$ and in any case it would be fine if we could avoid such linguistic contortions. What plays in (8) the role that is played in (7) by the word 'is'? Why is 'Socrates walk' no more a predication than 'Ann lazy'? The verb-ending does to 'walk' what 'is' does to 'lazy': it transforms a non-predicate into a predicate. In an expanded sense of 'copula' we might as well say that in (8) the verb-ending is the copula. ${ }^{25}$

Frege, not exactly famous for being a friend of the copula, saw this quite clearly:

(Frege) Often the word 'is' serves as copula, as a mere form-word of the Aussage. As such it can sometimes be replaced by a verb-ending. Compare, for example, 'this leaf is green' and 'this leaf greeneth'. ([Oft dient das Wort 'ist'] als Kopula, als bloßes Formwort der Aussage. Als solches kann es zuweilen durch die bloße Personalendung vertreten werden. Man vergleiche $z . B$. 'dieses Blatt ist grün', 'dieses Blatt grünt'.) (Frege 1967a, 194)

In the word 'greeneth' the verb-ending replaces the copula, while the verb-stem indicates the proper content. ([In dem Wort 'grünt'

${ }^{23}$ (Whately 1826), quoted after Prior $(1976,50)$, who calls the book "our English Summulae" (16).

${ }^{24}$ Actually, Whately's Copula + Adjective example does seem to capture the meaning of the verb (in its intransitive use), and for predicates like 'smokes' which also have a dispositional reading, the combination Copula + (indefinite article + nomen agentis) delivers a synonym - for this very reading: 'is a smoker'.

${ }^{25}$ Wiggins $(1984,318)$ and Strawson $(1997,85 ; 1990,318 ; 1994,24)$ do say it, and I shall follow suit. 
vertritt] die Personalendung die Stelle der Kopula..., während der Stamm einen eigentlichen Inhalt anzeigt. ${ }^{26}$ )

When apostrophizing the Christmas fir-tree, Germans did not sing 'Thou art green in winter' but rather 'Thou greenest in winter [Du grünst im Winter]'. (These days Germans no longer sing.) The component of the predicate 'is green' which 'indicates the proper content' is the general term. In an expanded sense of 'general term' we might as well say that in the one-word predicate 'greeneth' the verb-stem is the general term.

In calling the copula 'is' a mere form-word Frege does not declare it to be semantically irrelevant. What does he mean by 'Aussage'? This term is often used in the sense of 'Behauptung (statement, assertion)', but the presence of the copula in a well-formed sentence does not ensure that the sentence is a proper vehicle for making a statement (ein Behauptungssatz, a declarative sentence), as you can see from the interrogative 'Is Ann lazy?'. Actually, 'Aussage' in Frege is not an alternative title for the kind of speech-act he calls Behauptung. ${ }^{27}$ In traditional German grammar-books the predicate is often called the Aussageteil of a sentence, and this usage stands behind Frege's phrase 'bloßes Formwort der Aussage': it is meant to pick out that element of a certain part of a sentence $S$ in virtue of which that part is the predicate of $S .^{28}$ So Frege, too, seems to think of the copula as a predicate-forming operator on general terms.

Now let us consider our elementary predication

(7) Ann is lazy

${ }^{26}$ (Frege 1967c, 101). Cf. (Frege 1976, 154).

${ }^{27}$ Frege uses the noun 'Aussage' and the verb 'aussagen' primarily in contexts like Sentence $\mathrm{S}$ contains an Aussage about X' and 'In S something is ausgesagt about X'. This is remarkably close to Russell's use of 'assertion' in the Principles: "We may say, broadly, that every proposition may be divided, some in only one way, some in several ways, into a term (the subject) and something which is said about the subject, which is something I shall call the assertion. Thus 'Socrates is a man' may be divided into Socrates and is a man... [I]t might be said: 'Socrates was a philosopher, and the same is true of Plato.' Such statements require the analysis of a proposition into an assertion and a subject” (Russell 1964, $\$ 43$ ). (In $\$ 48$ Russell offers ‘A is greater than B' as an example of a "proposition” that is multiply decomposable.)

${ }^{28}$ In a letter Frege wrote that the copula "has no sense of its own and only serves to mark the predicate as such (keinen eigenen Sinn hat und nur das Prädikat als solches kenntlich macht)" (Frege 1976, 156). The second part of this remark confirms my intepretation, and it is plausible in itself. The claim that only the general term in the predicate 'is lazy' has a "sense of its own" would be false if it were meant to deny that the copula makes its own distinct contribution to what one grasps when one understands the expression 'is lazy' as a predicate. The copula does certainly not lack conventional linguistic meaning. But then, there are ever so many conclusive reasons for not identifying Fregean Sinn with conventional linguistic meaning. 
as a premiss on which we can apply existential generalization. From (7) we can derive

(9) Somebody is lazy

There is somebody who is lazy

$\exists x(x$ is lazy $){ }^{29}$

In moving to (9) we quantify into the position of a singular term, and that's something we also do in our language when we move from the quasi-Platonic counterpart of (7), namely

(10) Ann exemplifies laziness,

to the existentially quantified conclusion

(11) Ann exemplifies something

There is something that Ann exemplifies

$\exists x$ (Ann exemplifies $x)$.

As far as logical grammar is concerned, each of these existential quantifications would receive Quine's (and anybody else's) blessing. Conclusions (9) and (11) both comply with a principle which Quine upheld of early and of late:

(Quine) Variables are pronouns, and make sense only in positions which are available to names. (Quine 1976, 198)

[S]ingular terms are accessible to positions appropriate to quantifiable variables, while general terms are not. (Quine 1974, 220)

To put the predicate letter ' $\mathrm{F}$ ' in a quantifier... is to treat predicate positions suddenly as name positions, and hence to treat predicates as names... Variables eligible for quantification therefore do not belong in predicate positions. (Quine 1970, 66-67)

By Quinean lights, (non-substitutional) quantification is always nominal, or first-order, quantification. When he says, 'variables are pronouns', he means that they are pro-names, i.e. place-holders for singular terms. It is universally agreed that variables are pro-forms, but that they can only be pro-names is very implausible. In the sentence 'Not only Ann is lazy, Ben is so as well' the proform 'so' is an anaphoric place-holder for 'lazy', and 'There is something

${ }^{29}$ Strictly speaking, the Loglish formulation is equivalent with the others only if we take the range of the variable ' $x$ ' to be restricted to persons. (Cf. (Dummett 1973, 36-37) on the difference between restricted and unrestricted quantification.) 
Ann and Ben both are' seems to be as significant as 'There is something Ann and Ben both exemplify'. Therefore many have objected to Quine that the argument

(7) Ann is lazy, so

(12) Ann is something There is something Ann is $\exists \phi($ Ann is $\phi)$

is just as valid as that from (7) to (9). ${ }^{30}$ Here we quantify into the position of 'lazy', but in making this move we do not "suddenly treat that position as name position" (as Quine suspects). This becomes clear as soon as we expand our conclusion by a 'namely' rider: 'Ann is something, namely lazy'. The (second) 'is' in (12) is the copula from (7), a copula is not a sentenceforming operator on singular terms, so the 'namely' rider for (12) cannot present a name.

As regards information value there is a vast difference between (9), $\exists x(x$ is lazy)', and (12), ' $\exists \phi(\mathrm{Ann} \text { is } \phi)^{\prime}:{ }^{31}$ It is not a matter of course that anybody is lazy, but it goes without saying that good old Ann is something or other. If we do not want to force open doors in using quantifications in the style of (12) we have to take a deeper breath and say, for example,

(13) Ann is something reprehensible $\exists \phi($ Ann is $\phi$ \& it is reprehensible to be $\phi)$.

But as regards information value, (9) does not seem to be better off than (12): That Ann has some property or other is hardly electrifying (Strawson 1959, 237). So the fact that (12) does not convey any news does not give any reason for declaring it to be linguistically meaningless, and for all I know it has never been offered as a reason for such a verdict.

Since the copula of the premiss (7) survives in the conclusion (12), the position quantified into is not that of a predicate, but that of a general term. But the term 'lazy' is not a name either, so the objection stands: the variable in our quantification is not a pro-name. ${ }^{32}$ The move from (7) to (12)

${ }^{30}$ E.g. (Geach 1951, 132-133), (Sellars 1963), (Strawson 1971b, 65; 1974b; 1974a, 32-34), (Prior 1971, 35-37), (Dummett 1973, 61, 214 ff), (Boolos 1975), (Davies 1981, 136-142), (Künne 2007, 105-108, 118-119). If we may take Peter Simons at his word, a whole nation once opposed this aspect of Quine's conception of quantification: "All Poles rejected it" (Simons 1997, 263).

${ }^{31}$ (Strawson 1971b, 72-73, 1974b, 84).

${ }^{32}$ In any case, there are more quantifiers in natural languages than are dreamt of in Quine's philosophy of logic. From 'A and B met in the garden [at midnight]' we can infer, 'A and B met somewhere [somewhen]'. This is quantification into adverbial positions, as the ap- 
also shows that the predicate 'is lazy' is by no means a semantically seamless whole that contains the general term, as Quine put it, "merely as a constituent syllable comparable to the 'rat' in 'Ann."' (Quine 1974, 220). Surely we cannot quantify (non-substitutionally) into the position of a syllable.

Looking back at (Quine), we see that the verdicts in the second and third passages do not coincide. The ' $\phi$ ' in (12) does not occupy the position of the predicate letter in the schema 'Fa', but that of the place-holder for general terms in the schema 'a is F.' The expressions which I take to be perfectly "accessible to positions appropriate to quantifiable variables" are general terms, not predicates. ${ }^{33}$

Similarly, from the proposition that

(8) Socrates walks

we can not only conclude that there is at least one walker but also that

(14) Socrates does something. There is something Socrates does. $\exists \phi($ Socrates $\phi s)$.

Strawson is completely right when he says:

(Strawson 2) 'Socrates does something' (or 'Socrates is something') is just as good, and just as direct, a generalization from 'Socrates swims' (or 'Socrates is brave') as 'Someone swims' (or 'Someone is brave') is. The phrase 'does something' ('is something') replaces specificity with non-specificity just as the phrase 'someone' does. (Strawson 1974a, 33)

When moving to (14) we quantify into the position of the verb-stem, but this is not to "treat this position suddenly as name position", as can be seen from

propriate 'namely' rider shows: 'namely in the garden [at midnight]'. Surely this does not force us to view adverbials as singular terms. Cf. (Strawson 1971b, 72, n. 2; 1974b, 73-75; 1997, 5), (Prior 1971, 37) and the excerpts from the Oxford English Dictionary in (Rayo and Yablo 2001, 91 n. 1).

${ }^{33}$ In sect. 6 above, I took the indefinite article, as it occurs in 'Ann is a philosopher', to be part of the general term. This is a (minor) deviation from standard usage: Usually, naked nouns are classified as general terms (cf., e.g., Quine 1974, 217 et passim), and Strawson concurs when he talks of "a copula such as 'is' or 'is $a$ ' or the inflections which yield a finite form of the verb" (Strawson 1997, 85, my italics; 1990, 318; 1994, 24). I can now motivate my deviant usage. Just as 'Ann is lazy' implies 'There is something Ann is (namely lazy)', so 'Ann is a philosopher' implies 'There is something Ann is (namely a philosopher)'. In both cases, I take it, the 'namely' rider specifies the general term. So the letter ' $F$ ' in 'Ann is F' permits replacement by 'a man' just as well as by 'lazy'. (In German the indefinite article is sometimes optional ['Ich bin Philosoph'], but not always ['Bukephalos ist ein Pferd'].) 
the expansion of our conclusion, 'He does something, namely walk. ${ }^{34}$ Now just as in the case of (12) it needs to be emphasized that the position quantified into when moving to (14) is not that of a predicate. In natural languages like English or German there simply is no such thing as quantification into predicate position. This difference between our language and the Conceptual Notation of the venerable Quantifex Maximus tends to be overlooked by both friends and foes of non-nominal quantification. ${ }^{35}$ But the point to be made against the Quinean obsession with name variables remains entirely unaffected by this observation, for neither in (14) nor in (12) do we quantify into the position of a singular term.

We can now characterize the special semantical status of the copula as follows: The only word position in (7) which one cannot quantify into is that of the copula. ${ }^{36}$ Invoking a distinction to be explained in sect. 9, we can say: the copula in any of its guises does not denote anything, nor does it connote anything. Consequently, it does not denote, and it does not connote, exemplification. ${ }^{37}$ Notice that the copula in

(10) Ann exemplifies laziness,

is not the word 'exemplifies', for that is a two-place predicate. The copula in (10) is the verb-ending, and the stem of that verb is the general term that connotes exemplification.

Quine has always maintained that the existential quantifier is the formal counterpart to everyday locutions like 'there is an object (entity) such that'. ${ }^{38}$ This reading is of a piece with his conception of variables as pro-names, and it distorts his view of non-nominal quantifications. If the 'is' in (12) is the copula of $(7)$, then (12) is not tantamount to 'There is an object such that Ann is it', and (14) can certainly not be understood in the sense of 'There is an object such that Ann does it', for the latter does not make any sense at all. Unlike 'there is an object' the quantificational expression '(there is)

${ }^{34}$ From 'The owl complains to the moon' we can infer 'There is something she does (viz. complain to the moon)'. The line in Thomas Gray's 'Elegy' which is echoed in the premiss, 'The moping owl does to the moon complain', makes it easier to recognize that in the conclusion we quantify into the position of a verb-stem. The corresponding proform of laziness is 'so', as witness 'The owl complains to the moon, and so does the wolf'.

${ }_{35}$ Exceptions are (Dudman 1976, 80, 83), (Rundle 1979, 110-111), (Wiggins 1984, 317, 326) and (Strawson 1990, 318; 1997, 5).

${ }^{36}$ When I say 'quantification' I always mean non-substitutional quantification. Substitutionally we can quantify into any position if it is occupied by an element of a class of permissible substitutes that was fixed in advance (e.g. the class of all binary connectives).

${ }^{37}$ Similarly (Wiggins 1984, 318, 327) and (Strawson 1997, 84; 1994, 25). Unfortunately their use of 'stand for' blurs the difference between denotation and connotation.

${ }^{38}$ Thus (Quine 1976, 198; 1961, 102; 1960, 242; 1969, 97, 106; 1970, 89). 
something' is trans-categorial: we can use it for quantifying into singular and general term positions.

\section{Non-Nominal Quantification (II)}

Now what about quantification into sentence positions, as in the right branch of (MOD)?

$$
\text { (MOD) } \forall x(x \text { is true } \Leftrightarrow \exists p(x=[p] \& p))
$$

Clearly, the quantifier ' $\exists p(\ldots p \ldots)$ ' cannot be the quantifier of nominal, or first-order, logic, for the sentence operator ' $\&$ ' cannot be followed by a placeholder for a singular term. (Expressions like 'Logicism', 'Frege's most famous thesis in the philosophy of mathematics' or 'that arithmetic is a branch of logic' cannot appear as conjuncts in a conjunction, anymore than 'Paris' or 'the capital of France' can.)

Is there such a thing as quantification into sentence position in a natural languages such as English? Surely, the operator 'something', transcategorial though it is, does not span the category Sentence. Wilfrid Sellars' suggestion to read ' $\exists p(p)$ ' as 'Something.' cannot be taken seriously (Sellars 1963, $255 ; 1974,299)$. Let us start with an easier question: Is there such a thing as a prosentence of laziness? Yes, there is: Franz Brentano pointed out that in German ' $j a$ ' is used as a prosentence (Fürsatz) of laziness, and his pupil Kazimierz Twardowski also emphasized this. ${ }^{39}$ Up to a point, we can reproduce the effect in English. 'Is it raining?' - 'Yes.' 'Regnet es? Wenn ja, so bleibe ich lieber hier', in other words: 'Is it raining? If so, I'd rather stay here'. (Notice that in both examples the prosentence acts as deputy for the declarative counterpart of its interrogative antecedent.) Unfortunately, 'yes' (or 'so') cannot be substituted for sentences (of the declarative type) in all contexts: thus in 'Ann believes that Vienna is large, and Ben believes that Vienna is large' you cannot supplant the second embedded sentence by 'yes' or 'so.' ${ }^{\circ}$

Dorothy Grover, Joseph Camp and Nuel Belnap (Grover, for short) have argued that English does provide us with a generally availabe prosentence. Suppose Ben says,

(7) Ann is lazy,

and Jim agrees,

(15) That is true.

\footnotetext{
39 (Brentano 1930, 76 (65)), (Twardowski 1999, 40 f). (The English translation does not quite preserve the point: (Twardowski 1999, 150).)

${ }^{40}$ Incidentally, the proform 'so' is transcategorial, for it can be substituted for expressions of various categories: 'Ann is lazy, and so is Ben'; 'Ann moves gracefully, and so does Ben'.
} 
One is inclined to hear Jim's remark as an utterance of a subject-predicate sentence. Thus understood the demonstrative 'that' in his utterance of (15) is used to refer to what Ben said (the proposition that Ann is lazy), and 'is true' ascribes truth to this object. Grover pleads for a different reading of (15). She regards the whole sentence 'That is true' as a generally available prosentence of laziness. ${ }^{41}$ If we understand this sentence as a prosentence, it no longer requires a subject-predicate analysis. Using the terminology of late medieval logicians we might say that by Grover's lights 'true' is only a syncategorematic, or consignificative, component of 'that is true.' In Jim's utterance of (15) the prosentence deputizes for its antecedent, i.e. Ben's utterance of 'Ann is lazy'. Hence nothing is referred to in the utterance of the prosentence which is not also referred to in its antecedent. After all, under Grover's reading of 'that is true' its utterance acquires all its content from its antecedent, so there cannot be any additional reference in 'that is true. ${ }^{42}$

It should be clear at the outset that this proposal is singularly unattractive if one wants to provide the right-hand side of (MOD) with a reading in English. It would amount to explaining the predicate 'is true' in terms of a predicate that contains 'true' as a syncategorematic component. This would be unpleasantly close to circularity. In Grover's hands the proposal is meant to serve the very different goal of establishing truth-theoretical nihilism: it is the first step in her attempt to show that in our common truth-talk we do not really ascribe truth to anything. I have argued at length in $C T$ that the attempt fails. Let me just briefly rehearse one of the difficulties which Grover has to face already at her first step. Consider the following comments on a claim which has come under attack:

(16) That is true, so it cannot be inconsistent

(17) That is true, even if it is incompatible with a dogma of the church.

In (16) and (17) a predicative reading of the second sentence is obligatory. So how does the anaphoric subject-expression 'it' acquire its referent? From

${ }^{41}$ Grover points out that in many contexts 'it is true' has an equal claim to be conceived of as a prosentence of laziness. For ease of exposition I shall neglect this here.

${ }^{42}$ Horwich's sketch of Grover's idea of prosentences of laziness runs as follows: "Just as one might use the pronoun 'he' instead of repeating a name (as in 'John said he was happy'), so one might say 'That's true' instead of repeating the sentence just asserted. Evidently this is a perfectly correct observation as far as it goes. However,..." (Horwich 1998, 125). The comparison with pronouns of laziness is apt (and echoes Grover's own procedure), but the example chosen is inept. Since John may suffer from amnesia, 'John said he was happy' may express a truth while 'John said John was happy' yields a falsehood. This kind of divergence is excluded when 'That is true' goes proxy for a declarative sentence just uttered. When Grover introduces the comparison, she uses examples like the pair (1) / (1a) in the last subsection. 
the demonstrative in the first sentence of (16) and (17), one feels inclined to answer. But then, that sentence, too, is a predication, and its grammatical appearance does not belie its logical structure. ${ }^{43}$ In my book I go on to show that Grover cannot offer a convincing reading of the quantifier which allegedly binds the alleged prosentence 'that is true', and that all varieties of truth-theoretical nihilism finally come to grief over propositionally unrevealing truth-talk like 'Logicism is true,' 'The Pythagorean Theorem is true', 'Church's thesis is true', etc. Grammatical appearances are not misleading: in such sentences a decent singular term is combined with a genuine predicate. Peter van Inwagen also finds Grover's attempt to explain sentential quantification by means of the alleged prosentence 'That is true' wanting. ${ }^{44}$ Disappointed by the performance of Grover's alleged prosentence, van Inwagen gives up with a sigh:

(Van Inwagen) Maybe there are prosentences hiding somewhere in the jungle of natural language, and perhaps they can be used to make sense of sentential quantification. But if there are natural-language prosentences, I have no idea what they might be. (van Inwagen 2002, 222)

What he has been looking for in vain has actually been found in the jungle a long time ago: Wittgenstein's prosentence 'Es verhält sich so' does the job of which van Inwagen despairs. In view of our quotidian use of locutions like 'However she says things are thus they are' it is misleading to call the language of the modest account a "new form of quantification" or a "new linguistic apparatus", as Horwich does (Horwich 1998, 37, 4 fn.). What is comparatively new is its notation in Loglish. But the logicians' notation for nominal or first-order quantification is not so very ancient either, so this kind of age comparison is not to the point.

I have tried to convince you that there is such a thing as (non-substitutional) quantification into the positions of general terms and of sentences in a natural language like English. So far I have not said a single word about the semantical account of such quantifications. In the next two sections I shall try to make good for this omission. Again I will start with quantification into general term positions, because my proposal here is analogous to the one I have in mind for quantification into sentence position: I shall argue along exactly parallel lines when I turn to the latter kind of quantification that is invoked on the right-hand side of (MOD).

${ }^{43}$ This sharpens, I think, a similar objection raised in (Forbes 1986, 37, 51-52 fn. 6) and (Dodd 2000, 40-42). Both authors turn it against (Grover et al. 1992, 101-103).

${ }^{44}$ In (CT, Ch. 2.2.3) we reached the same conclusion. 


\section{General Terms, Properties, and Two Styles of Quantification}

The semantic account of predication I adopted in $C T$ assigns properties to concrete general terms: The general term 'lazy' signifies or connotes the property of being lazy, and all and only those objects to which this term applies exemplify this property. A general term $G$ in language $L$ connotes a property $\mathrm{X}$ iff in $\mathrm{L}$ the combination Copula $+G$ serves to ascribe $\mathrm{X}$ to an object. Only general terms stand in this relation to properties. So the picture I recommend is this:

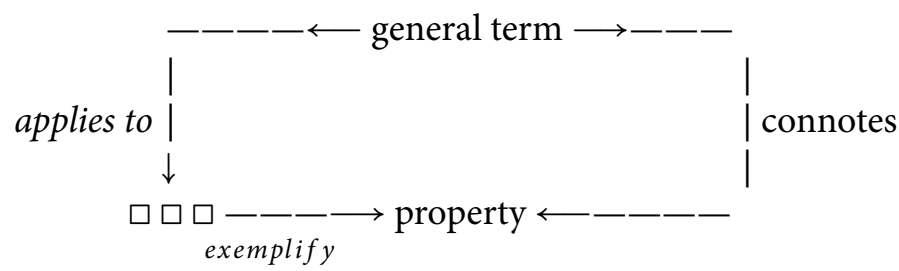

The property that is connoted by a general term $G$ is designated or denoted by various singular terms, most prominently by the singular term that can be obtained from $G$ by nominalization. (This is the point where my use of 'connote' and 'denote' converges with Mill's.) In a rich language like ours we can ascribe a property to an object, using a copula and a general term, and we can make an identifying reference to it, using a singular term. The ascriptive mode of "introducing" a property "into discourse" 45 has priority over the referential mode: you are not able to refer to properties unless you have learnt to ascribe them. Now it is a remarkable fact that sometimes we use both modes almost in one and the same breath. Consider the following dialogue between Mr Eulogist and Mrs Faultfinder:

(A) Mr E: Ann is perfect, she has not got a single vice. Mrs F: No, you are wrong:

(A1) Ann is lazy.

(A2) Laziness is a vice.

(A3) So Ann has at least one vice.

Her argument is intuitively valid. (An argument is valid (in my usage of this epithet) iff it is conceptually impossible for all the premisses to be true without the conclusion being also true. (Logical concepts are a sub-kind of concepts. 'Ann is a widow, so Ann was married' and 'Ann and Ben are ill, so Ann is ill' are equally valid, but only the latter is logically, or formally, valid.)

\footnotetext{
${ }^{45} \mathrm{I}$ adopt this way of putting things from Strawson. For references see $(C T, 366)$.
} 
The semantic account I recommend allows us to explain why the argument in $(\mathrm{A})$ is valid. The general term in line ( $\mathrm{A} 1)$ connotes a property, sc. laziness, which is denoted by the singular term in $\left(\mathrm{A}_{2}\right)$. If the premisses are true, then that property is both exemplified by Ann and a vice, and it is conceptually impossible for that to be true while the conclusion $\left(\mathrm{A}_{3}\right)$ is not true. As it stands, the argument in (A) is not formally valid. Never mind, it is valid, and it can be turned into a formally valid argument by a transformation of (A1) which every speaker who understands the argument in (A) is ready to carry out:

$\left(\mathrm{Al}^{*}\right)$ Ann has (possesses, exemplifies) laziness.

By assigning properties to general terms we can make sense of the interaction between concrete general terms and abstract singular terms as witnessed in dialogue $(\mathrm{A})$.

Now in $\left(A_{3}\right)$ we have quantification into the position of a term that denotes a property, hence nominal quantification. What about quantification into general term position? The semantical account I favour is this: Sentences like

(12) $\exists \phi($ Ann is $\phi)$

are non-nominal quantifications over properties. ${ }^{46}$ The bound variable ' $\phi$ ' is associated with a range of objects, viz. properties, which are its values. So it is (not substitutional but) objectual, or ontic, quantification. But it is quantification into general term position. Hence it is not nominal quantification like 'Somebody is lazy' or

(11) $\exists x($ Ann exemplifies $x)$.

Permissible substituends for ' $\phi$ ' do not denote the values of this variable. That is done by singular terms such as 'laziness' which can replace the variable ' $x$ ' in (11). Permissible substituends for ' $\phi$ ' connote the values of this variable. So this variable resembles those in nominal quantifications in having values, but having a value is not the same for both. Sentence (12) expresses a truth if and only if there is at least one object within the range of its variable, i.e. a property, which meets the following condition: the object denoted by 'Ann' is such that it exemplifies that property. ${ }^{47}$ The truth-conditions of (12), thus understood, and those of (11) coincide; which is not to say that these

${ }^{46}$ Cf. (Strawson 1990, 318; 1997, 5 and (Soames 1999, 48).

${ }^{47}$ When Boolos defends the assumption that sentences like (1) are quantifications over sets against Quine's accusation (cf. CT, 361-362) that this implies (mis)treating predicates as names, his argument has exactly the same structure: (Boolos 1975, 511). 
sentences have the same meaning. (The sentences 'ABC is triangular' and 'ABC is trilateral' are not synonymous, and yet they have the same truthconditions.) But a speaker who understands both (12) and (11) cannot take one of these sentences to express a truth without immediately being ready to take the other to express a truth as well: so they are cognitively equivalent. (It would be absurd to claim, 'To be sure, there is something $a$ and $b$ both are, but I wonder whether they really have anything in common'. If in the course of a conversation we accept an assertoric utterance of ' $a$ and $b$ have nothing in common', then our reason is not that we subscribe to "nominalism" and take what is literally said to be true whatever, or whoever, $a$ and $b$ may be. Rather, we accept that utterance because we hear it as a hyperbole, as a rhetorical overstatement: what is literally said is false, but a tacit restriction to a contextually relevant sub-kind of characteristics is in place, e.g. to features one tends to dislike in a person, and the speaker wants to convey the message that $a$ and $b$ have none of those features in common. If you strongly dislike Ann's mother you will be pleased to be told before your first meeting with Ann, 'She has nothing in common with her mother.)

Proceeding along these lines we conceive of quantifications into the position of general terms as (non-nominal) quantifications over the very same entities which we saw reason to assign to general terms quite independently of quantifications into their position. So this gives us a pleasingly unified picture.

\section{Sentences, Propositions, and Two Styles of Quantification}

Let us now turn to propositions. In a rich language like ours we can assert a proposition by uttering a declarative sentence that expresses it, and we can make an identifying reference to it, using a singular term, e.g. a that-clause. Clearly the former activity has priority over the latter: you are not able to refer to propositions unless you have learnt to use sentences that express them. Now it is a remarkable fact that sometimes we do both things almost in one and the same breath. Consider the following dialogue:

(B) $\mathrm{Mr} \mathrm{E}$ : Ben is very careful, he never denies anything that is true. Mrs F: Once again you are wrong:

(B1) Ben's wife is having an affair.

(B2) That Ben's wife is having an affair is vehemently denied by Ben.

(B3) So some truth is vehemently denied by Ben.

Again Mrs Faultfinder's argument is faultless. If our semantic account of the language used in dialogue (B) assigns propositions to sentences we can 
explain why her argument is valid. The sentence in line (B1) expresses a proposition, sc. that Ben's wife is having an affair, which is denoted by the that-clause in $\left(\mathrm{B}_{2}\right) .^{48}$ If both premisses of the argument in (B) are true, then the proposition expressed in (B1) and denoted in (B2) is both true and vehemently denied by Ben, and it is conceptually impossible for that to be true without the conclusion $\left(\mathrm{B}_{3}\right)$ being also true. As it stands, the argument in (B) is not formally valid. Never mind, it is valid, and it can be turned into a formally valid argument by a transformation of (B1) that every speaker who understands (B) is ready to carry out:

$\left(\mathrm{B}^{*}\right)$ That Ben's wife is having an affair is true.

By assigning propositions to sentences we can make sense of the interaction between sentences and abstract singular terms as witnessed in dialogue (B).

Now in $\left(B_{3}\right)$ we have quantification into the position of a singular term, hence nominal quantification. What about quantification into sentence position? The semantical account I favour is this: sentences like

$$
\text { (18) } \exists p(p)
$$

are sentential quantifications over propositions. The variable ' $p$ ' is associated with a range of objects, viz. propositions, which are its values. So it is objectual quantification. But it is quantification into sentence position. Hence it is not nominal quantification like

(19) $\exists x(x$ is true $)$.

Permissible substituends for ' $p$ ' do not denote the values of this variable. That is done by singular terms such as 'logicism,' 'Frege's most famous thesis in the philosophy of mathematics' or 'that arithmetic is a branch of logic' which can replace the variable ' $x$ ' in (19). Permissible substituends for ' $p$ ' express the values of this variable. So this variable resembles those in nominal quantifications in having values, but having a value is not the same for both. Sentence (18) expresses a truth if and only if there is at least one object within the range of its variable, i.e. a proposition, which is true. The truthconditions of (18), thus understood, coincide with those of (19). This is not to say that these sentences have the same meaning. (The sentences 'Snow is white' and 'Snow is white, or snow is white' are not synonymous, and yet they have the same truth-conditions.) But they are cognitively equivalent: somebody who understands 'Things are somehow' and 'Something is true' cannot accept one message without immediately being ready to accept the other message as well.

${ }^{48}$ Contra Davidson I maintain in $(C T, 264-265,329)$ that the pronoun in (B2) no more denotes an utterance or inscription than does the pronoun in (A2). 
Proceeding along these lines we conceive of quantifications into the position of sentences as (non-nominal) quantifications over the very same entities which we saw reason to assign to sentences quite independently of quantifications into their position. So this gives us a pleasingly unified picture.

\section{Commitment and validity}

As her arguments in (A) and (B) show, Mrs Faultfinder (like all of us) is very good at reifying or, if you prefer Greek, at hypostatizing. Is she committed to (acknowledge the existence of) properties and propositions? Well, the word 'commitment' has a rather solemn air. The kind of ontological commitment that matters for semantics is, as it were, ontological commitment light, or non-philosophical ontic commitment. Suppose a "nominalist" philosopher of mathematics is asked by his little daughter whether there are any prime numbers between 21 and 27 , and unguardedly he answers, "Yes, dear, there is exactly one prime number between 21 and 27." But then suddenly he remembers his philosophy, and he goes on to say, "But of course, that was only a picturesque way of talking: there are not really any numbers." ${ }^{49} \mathrm{He}$ should not be surprised if his daughter will never again ask him for help... The philosopher's first statement betokens what I call ontological commitment light. Or suppose a philosopher of "nominalist" persuasion is asked by her little son who is annoyed by her constantly contradicting his father, "Do you never ever believe anything Daddy is convinced of?" "Oh no," she hastens to reply, "there are many things we both believe". But then she remembers her philosophy, coughs and adds in a dispirited tone of voice: "but of course, there is not really any such thing as what is believed, be it by one or by several people." Presumably her son will now stare at her with a blank... Again, the philosopher's first statement betokens what I call ontological commitment light. A philosopher "who is suspicious of abstract entities" like properties, propositions and numbers, Rudolf Carnap once remarked, will "probably ... speak about all these things like anybody else but with an uneasy conscience, like a man who in his everyday life does with qualm many things which are not in accord with the high moral principles he professes on Sundays" (Carnap 1950, 205). The non-philosophical ontic commitments that matter semantically are those one incurs on work-days, so to speak. Vices are properties it is bad to have, and truths are true propositions, so in accepting her conclusions Mrs Faultfinder is committed to properties and propositions in the same sense in which the father who answers his daughter's arithmetical question is committed to numbers when he asserts that there is a prime number between 21 and 27. After all, if there are

\footnotetext{
${ }^{49}$ The story is due to Alan Ross Anderson (1959).
} 
prime numbers then there are numbers.

A speaker who assertively utters the nominal quantification

(11) $\exists x($ Ann exemplifies $x)$ or

(19) $\exists x(x$ is true $)$

thereby incurs an ontological commitment (light) to properties or propositions. Does this also hold of a speaker who assertively utters the nonnominal quantifications (12) or (18)?

(12) $\exists \phi($ Ann is $\phi)$

(18) $\exists p(p)$

If Ben asserts that there is something Ann is, he does not presuppose the existence of any object which he was not yet committed to when he said, 'Ann is lazy'. I do not mean to deny this. If a theorist in his attempt to give the semantics of a language $\mathrm{L}$ explicitly invokes the assumption that there are properties, he does not thereby ascribe this commitment to the speakers of L. He may reasonably refrain from doing the latter. A semanticist may take certain binary connectives in $\mathrm{L}$ to be associated with truth-functions, mappings from pairs of truth-values to truth-values, but steadfastly refuse to ascribe to the speakers of $\mathrm{L}$ a commitment to functions and truth-values (Evans 1982, 74). One can scarcely be committed to accepting the statement that there are F's if one has not even partially mastered the concept $F$. Speakers of $\mathrm{L}$ do not incur a commitment to properties before they employ abstract general terms that apply to them and endorse claims like 'Ann has some bad properties' or 'Napoleon had all qualities of a great general'. (The workaday concept of a property that is used in $C T$ is such that you have mastered it if you have come to understand such humble statements.) At this point the commitments of L-speakers begin to line up with those of the semanticist who assigns properties to the general terms in $\mathrm{L}$ (as their connotata) and to variables in the position of those terms (as their values). The same holds mutatis mutandis for propositions. Speakers of $\mathrm{L}$ do not incur a commitment to propositions before they employ abstract general terms that apply to them and endorse claims like 'The Pythagorean Theorem is still unknown to most children in this school-room,' 'Something may very well be true even though it is incompatible with a dogma of the church', or 'Everything the witness said was refuted by the public prosecutor'. (The workaday concept of a proposition that I use in $C T$ is such that you possess it if you have come to comprehend such statements. Of course, somebody may have that concept even though the word 'proposition' does not belong to her vocabulary.) If L-speakers have reached that stage, they understand both (12) and (11), both 
(18) and (19), and since the members of these pairs are cognitively equivalent, they move as smoothly from one formulation to the other as they move back and forth between 'Ben is courageous' and 'Ben has courage'.

A negative answer to the question, 'Do we incur a commitment to any object other than Ann when we assertively utter 'Ann is lazy'?', does not imply that we commit ourselves only to the existence of Ann when we make that assertion. Participants in the debates about ontological commitments tend to take a Quinean presupposition for granted even if they reject Quine's views on quantification into general term position. Suppose somebody assertively utters the following non-nominal quantification:

(20) There is something which nobody is (namely omniscient).

Does she betoken an ontological commitment? The answer is 'No' if ontological commitments are always commitments to objects. Now Frege and Heidegger, to mention a rather unlikely couple, emphatically deny the Quinean antecedent. Functions in general and concepts in particular are not objects, the former says (and soon comes to regret this particular way of putting it), and the latter accuses traditional metaphysics of confusing being (Sein) with entities (Seiendes)..$^{50}$ Maybe Quine was far more right than he thought when he said, "Though no champion of traditional metaphysics, I suspect that the sense in which I use this crusty old word (sc. 'ontology') has been nuclear to its usage all along" (Quine 1951, 204). Of course, if one incurs an ontological commitment by stating that (20), then this commitment must already be present when one makes the more specific statement that

(21) Nobody is omniscient.

"And so it is", critics of the Quinean presupposition will reply. "In making the statement that (21) you commit yourself to there being something nobody is. Similarly, in asserting that Ann is lazy you commit yourself to there being somebody who is lazy and to there being something Ann is." I cannot see any fault in this reply.

Whether it is objectual or not, ontological commitment is primarily something that asserters and believers incur. ${ }^{11}$ By contrast, validity is a property

${ }^{50}$ A similar remark on this meeting of the extremes in (Künne 2007, ch. 3.3) was taken by Tobias Rosefeldt as a starting-point for an illuminating Fregean reconstruction of some of the things Heidegger says about the "ontological difference" (Rosefeldt 2003). Dummett has emphasized Frege's opposition to the Quinean presupposition a long time ago: "Quine's assumption that the question, 'What objects are there?', exhausts the content of the general ontological query, 'What is there?', is ... in sharp contrast with Frege's view" (Dummett 1973, 479).

${ }^{51}$ Philosophers who got used to Quine's idiom tend to say of a theory $\theta$ or a sentence $s$ that it is 
of arguments. An argument is valid if and only if it is conceptually impossible for (all) the premiss(es) to be true without the conclusion being also true. Logical concepts being a sub-kind of concepts, an argument may be valid without being logically, or formally, valid. The argument

(P1) Ann is lazy,

(C1) so $\exists \phi(A n n$ is $\phi)$

is formally valid, and so is the argument

(P2) Ann exemplifies laziness,

(C2) so $\exists x$ (Ann exemplifies $x$ ).

Now under my construal the conclusion of the former argument has the same truth-condition as that of the latter. The argument from $\left(\mathrm{P}_{1}\right)$ to $\left(\mathrm{C}_{2}\right)$ is not formally valid, but it is valid all the same. Its validity is already ensured by the conceptual impossibility of there being an object without any property. So let's modify the example:

$\left(\mathrm{P}_{3}\right)$ Ann is lazy, and it is reprehensible to be lazy,

(C3) so $\exists \phi($ Ann is $\phi \&$ it is reprehensible to be $\phi)$.

Under my construal $\left(\mathrm{C}_{3}\right)$ has the same truth-condition as

(C4) $\exists x$ (Ann exemplifies $x \&$ it is reprehensible to exemplify $x$ ).

In some possible world Ann has no property it is reprehensible to have, so $\left(\mathrm{C}_{4}\right)$, unlike $\left(\mathrm{C}_{2}\right)$, does not express a truth with respect to every possible world in which Ann exists. But there is no possible world with respect to which the premiss $\left(\mathrm{P}_{3}\right)$ expresses a truth without $\left(\mathrm{C}_{4}\right)$ doing so as well. For it is conceptually impossible that (Ann is lazy, and it is reprehensible to be lazy) although Ann has no property it is reprehensible to have. So my semantical proposal does not endanger the validity of the argument from $\left(\mathrm{P}_{3}\right)$ to $\left(\mathrm{C}_{3}\right)$. But it is not yet plain sailing, as we shall see in the next section.

But before confronting that heavy sea, let us consider how my semantical account fares with respect to validity in the case of sentential quantification. The argument

(P5) Ann is lazy,

ontologically committed to F's. I take that to be a case of metonymy ('The crown prefers...'): $\theta$ or $s$ is committed to F's, iff people would be (at least prima facie) committed to F's if they were to endorse $\theta$ or to utter $s$ assertively. (In (Quine 1961, 103-104) the priority is reversed.) 
(C5) so $\exists p(p)$

is formally valid (in higher-order logic), and the argument

(P6) The proposition that Ann is lazy is true,

(C6) so $\exists x(x$ is true $)$

is formally valid (in first-order logic). Now under my construal the conclusion of the former argument has the same truth-condition as that of the latter. The argument from $\left(\mathrm{P}_{5}\right)$ to $(\mathrm{C} 6)$ is not formally valid (neither in firstorder nor in higher-order logic), but it is valid all the same. Its validity is already ensured by the fact that it is conceptually impossible that nothing is true. So let's modify the example:

$\left(\mathrm{P}_{7}\right)$ Ann is lazy, but Ben denies that Ann is lazy,

(C7) so $\exists p(p \&$ Ben denies that $p)$.

Under my construal $\left(\mathrm{C}_{7}\right)$ has the same truth-condition as

(C8) $\exists x(x$ is true \& Ben denies $x)$.

It is not conceptually impossible that Ben does not deny any truth. But again, there is no possible world with respect to which $\left(\mathrm{P}_{7}\right)$ expresses a truth without (C8) doing so as well. For it is conceptually impossible that (Ann is lazy, but Ben denies that Ann is lazy) although Ben does not deny any truth. So my semantical proposal does not endanger the validity of the argument from $\left(\mathrm{P}_{7}\right)$ to $\left(\mathrm{C}_{7}\right)$.

\section{A Russellian Challenge}

There is a powerful objection, due to Boolos, Van Cleve, and Rayo \& Yablo ${ }^{52}$, against the semantical account of quantification into general term position which I favour. Since the objection does not attack sentential quantification, it is not directly relevant to (MOD), and one might brush it aside by saying: 'Oh, I do not believe in guilt by association.' But of course, I am not in the least inclined to this reaction. I see both varieties of non-nominal quantification in the same boat, as far as the 'objectual or not?' issue is concerned: that was the point of the analogy traced out in sections 8 and 9 above.

The argument, as given by van Cleve (and by Mark Textor), invokes the property variant of Russell's paradox. Some properties exemplify themselves. Like every other property, the property of being incorporeal is itself

\footnotetext{
${ }^{2}$ (Boolos 1984, 442), (van Cleve 1994, 582), (Rayo and Yablo 2001, 81-82).
} 
incorporeal, and the property of being self-identical, like everything else, is self-identical. But normally properties do not exemplify themselves. Laziness is not lazy, and diligence is not diligent; so these properties are not selfexemplifying. Let us call a property p-normal iff it does not exemplify itself. Then we can truly say:

(Q) Laziness and diligence are p-normal.

Now does the general term in $(\mathrm{Q})$ connote a property? Is there such a thing as the property of being p-normal? If so, the question arises whether it is itself p-normal. And the logically embarrassing answer is: if it is p-normal then it is not p-normal, and if it is not p-normal then it is p-normal. Hence there cannot be such a thing as the property of being $\mathrm{p}$-normal. Consequently, the general term in $(\mathrm{Q})$ does not connote, and the term which results from its nominalization does not denote, any property. In uttering (Q) we rightly say about a certain property that it does not exemplify itself, but we do not thereby ascribe a property to it. So, using 'p-normal' as abbreviation for 'non-self-exemplifying', we can say:

(R) There is something laziness and diligence both are (namely p-normal), but [as Russell taught us] there is no such thing as the property of being p-normal.

This statement seems to be consistent. If appearances are not deceptive then the truth-conditions of the first conjunct of $(\mathrm{R})$ cannot be those of a higherorder quantification over properties. So my account of quantification into general term position threatens to collapse.

Prima facie at least, three reactions to this problem seem to be possible:

(i) Appearances are deceptive. (R) is inconsistent, for the first conjunct can only be understood as a higher-order quantification over properties.

(ii) (R) is consistent, but we must understand the quantification in the first conjunct along other lines than in standard cases.

(iii) (R) is consistent, so quantifications into general term position should never be understood as quantifications over properties (or over anything else).

Let us put reaction (i) aside here. Boolos et al. plead for (iii), and other philosophers have also denied that variables in (non-substitutional) quantifications into the position of general terms have values. Higher-order quantification, they claim, is not a special kind of objectual quantification but 
rather sui generis. ${ }^{53}$ The delicate question is then, of course, what the semantics for such quantifications is to look like. Now suppose that our metalanguage is English and our object-language is a fragment of English enriched with the ' $\exists \phi$ '-quantifier. Then we can use the second-order quantifier in our metalanguage when it comes to specifying the truth-conditions of second-order quantifications in Loglish and say, for example: the sentence ' $\exists \phi(\mathrm{Ann}$ is $\phi)$ ' expresses a truth if and only if there is something the entity denoted by 'Ann' is. That's the key idea. ${ }^{54}$ I do not know of any argument that shows that an account of non-nominal quantification along this line cannot work. On the other hand, I do not think that (R) shows that the sui generis account, as one might call it, is the only game in town.

Reaction (ii) is at least as plausible, I think. If one reads the first conjunct of (R) as a higher-order quantification over properties, the conjunction is inconsistent. But there is a different reading under which $(\mathrm{R})$ is consistent and which does not boil down to alternative (iii). Here is a somewhat similar problem-case in the area of first-order quantification:

(S) There is an Olympian goddess who is depicted on several paintings in this gallery (namely Venus), but as we all know, there are no goddesses, Olympian or not.

This statement is inconsistent if the quantifier is given the same reading in both conjuncts. But the impression of inconsistency disappears if we understand the first conjunct along the following lines: 'There is a true positive answer to the question which Olympian goddess is depicted on several paintings in this gallery (namely the answer that Venus is depicted on several of those paintings).' Now (R) can be treated, and I think it should be treated, in a similar fashion. Enlightened by the property version of Russell's paradox we see that the expression 'There is' in the first conjunct of (R) should not be rendered by the quantifier ' $\exists \phi$ '. The first conjunct should rather be understood along the following lines: 'There is a true positive answer to the question what laziness and diligence both are (namely the answer that they are both p-normal)'. Thus we read the recalcitrant conjuncts in (S) and in (R) as first-order quantifications over propositions. ${ }^{55}$

The Russellian trouble has taught us that the conclusion of an argument of the form ' $a$ is F, so $a$ has F-ness' may not be true although the premiss is

${ }^{53}$ Following Prior (1971) I opted myself for this position in (Künne 2007, 118-123) (and I followed Prior also in remaining silent on semantical issues). Cf. (Boolos 1984, 449), (van Cleve 1994, 588), (Simons 1997) and the authors mentioned in the next footnote.

${ }^{54}$ Cf. (Bigelow 1988, 163-164), (Williamson 1999, 260-263), (Rayo and Yablo 2001, 78).

${ }^{55}$ Could one understand them as substitutional quantifications? "I am sceptical about the role of the substitutional quantifier for interpreting natural language", Kripke says (Kripke $1976,380)$. In (CT, 359-360), I explain why I find this reserve wise. 
true: in 'Laziness is p-normal, so laziness has p-normality' we move from a truth to an untruth. Consequently, we have to restrict the assumption that there is such a thing as the property of being thus-and-so whenever an object is truly said to be thus-and-so. So it should come as no surprise that we also have to restrict the assumption that there is such a thing as the property of being thus-and-so whenever it can be truly said of an object that there is something it is (namely thus-and-so). But if the general term ' $\mathrm{F}$ ' is not paradox-inducing, we can continue to say that the property of being $\mathrm{F}$ is ascribed to an object whenever that object is correctly asserted to be F. Similarly, if we have banned general terms that engender paradox, we can continue to read quantifications into the position of general terms as quantifying over those entities that we saw reason to assign to them quite independently of the use of second-order quantification.

\section{Expressing Propositions}

All philosophers who take truth to be primarily a property of propositions (and they make for an impressive assembly, including Bolzano, Frege, Cartwright, Strawson, Kaplan, Horwich, Alston, Soames, Lewis, and Schiffer) eventually have to face the question which condition a sentence as uttered on a certain occasion has to fulfil if it is to express such-and-such a proposition. But an adherent of the Modest Account is under an additional obligation: he has to answer this question without appealing to the concept of propositional truth. How is that to be done?

An advocate of the Modest Account can consistently accept the basic tenet of truth-conditional semantics. She can concede, for example, that one cannot know the lexico-grammatical meaning (the meaning, for short) of sentence S, 'That person is Boche', unless one knows that $\mathrm{S}$ expresses a truth in the mouth of a speaker $A$ at time $t$ if and only if the person referred to by $\mathrm{A}$ at $\mathrm{t}$ is German. This knowledge does not suffice for knowledge of the meaning of $S$, for one does not understand $S$ fully if one does not know that by using $S$ a speaker conveys an attitude of contempt for the person referred to, but circumspect friends of truth-conditional semantics will claim only that knowledge of truth-conditions is required for full understanding. (On the other hand, an advocate of the Modest Account will refrain from identifying the meaning of a declarative sentence with a proposition, one reason being that $\mathrm{S}$, without undergoing any alteration of its meaning, can be used to state many different truths and falsehoods.) Of course, even if acceptance of (MOD) does not oblige you to deny that there might be an illuminating answer, along truth-conditionalist lines, to the question when a sentence expresses a true proposition, you may have very good reasons for doubting that such an answer can really be given for a natural language. (I 
count myself among the sceptics.)

Putting it schematically, the question is, 'Under which condition does a sentence s express in language $L$, with respect to context $c$, the proposition that $p$ ?', and the special challenge for the advocate of (MOD) is to answer this question in such a way that the notion of propositional truth is not even tacitly invoked. The answer I propose is the universal closure of the following schema:

(Express) $s$ expresses in $\mathrm{L}$, with respect to $\mathrm{c}$, the proposition that $\mathrm{p}$, if and only if one can make most sense of the speakers of $L$ if one takes their serious assertoric utterances of $s$ in $c$ as statements to the effect that $\mathrm{p}$.

As against this one might argue:-A person who makes assertions must be aware that he or she is expected to aim at truth. So the concept of an assertion (statement) can scarcely be explained without invoking the concept of truth.-But is the premiss of this argument really correct? Can you not recognize your obligation as an asserter by coming to realize that you are expected to assert something only if you are justified in doing so? After all, the injunction to make only true assertions cannot call for acts that are not already called for by the injunction to make only warranted assertions. Of course, this reply needs to be supported by an argument to the effect that one can know when one is justified in making an assertion without yet having acquired the concept of truth. The supporting argument I appeal to in CT at this point is Michael Dummett's Argument From Embedding:

(Dummett) [T] he very concept of the truth of a statement, as distinct from the cruder concept of justifiability, is required only in virtue of the occurrence, as a constituent of more complex sentences, of the sentence by means of which the statement is made../.. [T] he transition is a major conceptual leap../.. [O]ur mastery of the most primitive aspects of the use of language to transmit information does not require even an implicit grasp of the concept of truth, but can be fully described in terms of the antecedent notion of justifiability. But comparatively more sophisticated linguistic operations, and above all, the use of ....conditional sentences, demand, for a mastery of their use, a tacit appeal to the conception of objective truth; and so we have, in our conceptual furniture, a place exactly fitted for that concept as soon as it is explicitly introduced. (Dummett 1993b, 193, 198, 199)

My dramatization of Dummett's point makes use of what I take to be his 
most convincing example, namely conditional predictions. Suppose that somebody assertively utters,

(22) If Ben will get married next Monday, then we will not see much of him for the next three weeks.

The conditional prediction is justified if the speaker is in a position to offer a conditional justification of the Consequent (= the proposition expressed by the consequent of (22)), but the condition under which the Consequent has to be justified is the truth of the Antecedent (= the proposition expressed by the antecedent of (22) in the same context). This condition is not the same as the condition which has to obtain for the Antecedent to be justified. (The justification condition for the Antecedent is met if the couple has put up the banns, many invitations have been sent, etc. The Antecedent shares this justification condition with the proposition that is in the same context expressed by 'Ben is going to get married next Monday'. The truth-conditions of these propositions diverge. What is now said in an utterance of 'Ben is going to get married' is not falsified if next Monday there will be occasion for reporting an embarrassing course of events: 'Ben was to get married today, but yesterday his fiancée eloped'. But what is now said by uttering 'Ben will get married next Monday' is true only if on Monday one can truly say, 'Ben is currently getting married', so under those embarrassing circumstances the Antecedent is falsified.) And what holds good for conditionals with an antecedent in the future tense, holds good for all conditionals: their use requires us to form an implicit conception of the truth of the statement that could be made by uttering the antecedent on its own, as distinct from the justifiability of that statement. (We need not yet have a word for this property in our repertoire, let alone be able to explain it.) As long as sentences which can be used as antecedents of conditionals are actually used only on their own, and for the purpose of transmitting information, knowing when it is reasonable to accept or reject what is said in their utterance, and hence an implicit conception of an assertion's being justified, is sufficient for employing them competently.

I have inserted the proviso 'and for the purpose of transmitting information', because one performs what Dummett calls a "more sophisticated operation" with a declarative sentence not only when one uses it within a conditional. Take future tense sentences again. More than knowledge of their justification conditions is required for competent use when they are employed in betting. If the better says today, 'Ben will get married next Monday', betting five pounds on it, he knows that the taker will pay him only on condition of the truth of what he says. He knows that the fact that the prediction is justified because all evidence available today speaks in its favour 
does not suffice for urging the taker to pay. So in this use, an assertoric utterance of 'Ben will get married next Monday' does not come to the same thing as an assertoric utterance of 'Ben is going to get married next Monday', for otherwise the bet could be settled already today. ${ }^{56}$ - At any rate, the fact that for competence in "less sophisticated" assertoric uses of declarative sentences only an implicit conception of justification is required shows that the notion of justification is not dependent on the notion of truth. (The same fact also refutes Frege's claim that one cannot assert anything without having mastered the concept of truth.)

So I cannot see that the biconditional (Express) involves a tacit appeal to the notion of truth, let alone that every informative biconditional which has the same left branch as (Express) is bound to involve an appeal to that notion. It would not be correct that the challenge I tried to cope with in this section is entirely due to my views on sentential quantification. It results rather from my deep agreement with Bolzano in assuming (i) that the notion of propositional truth can be explained, in some way or other, and (ii) that the notion of a proposition can be elucidated without invoking the notion of truth. ${ }^{57}$

A proposition $\mathrm{X}$ is true, according to the modest account, if and only if things really are as they are according to X. In this lecture I have tried to do what William James once formally asked his critic James B. Pratt to do, namely "to tell what this 'as'-ness consists in", for I share James' conviction that "it ought not remain a pure mystery." I hope to have dispelled the mystery. I take the modest account to offer common ground to all parties in the realism/antirealism controversy in which I take the realist side in the last chapter of my book.

\section{Bibliography}

Alston, W. P. (1996). A Realist Conception of Truth [RCT], Ithaca.

Anderson, A. (1959). Church on ontological commitment, Journal of Philosophy 56: 488-52.

Aquinas (1975). Summa contra gentiles. Book One: God, Notre Dame.

${ }^{56}$ Even this minor modification of Dummett's argument is based on Dummett: in (Meaning, 55), (Dummett 1993a, 255) and (LBM, 172) he himself makes the point about betting, which is neglected in the first statement of our quotation.

${ }^{57}$ Cf. (WL, Vol. 1: 76-78, 111-115, 121-125) and $(C T, 109-110)$. 
Arnauld, A. and Nicole, P. (1965). La Logique ou L'Art de penser, Stuttgart.

Berlin, I. (1980). Logical translation, Concepts and Categories, Oxford, pp. 56-8o.

Bigelow, J. (1988). The Reality of Numbers, Oxford.

Boghossian, P. (1990). The status of content, Philosophical Review 99: 157-84.

Bolzano, B. (1974). Beyträge zu einer begründeteren Darstellung der Mathematik, Darmstadt.

Bolzano, B. (1985). Wissenschaftslehre [WL], Gesamtausgabe, Vol. I, 11-I, 14, Stuttgart. Partially trans. as Theory of Science, Oxford 1972.

Boolos, G. (1975). On second-order logic, Journal of Philosophy 72: 509-527.

Boolos, G. (1984). To be is to be a value of a variable (or to be some values of some variables), Journal of Philosophy 81: 430-449.

Brentano, F. (1930). Wahrheit und Evidenz, Leipzig. Trans. as The True and the Evident. London 1966.

Burge, T. (1998). Frege on knowing the foundations, Mind 107: 305-347.

Carnap, R. (1950). Logical Foundations of Probability, Chicago.

Cartwright, R. (1987a). Negative existentials, Philosophical Essays, Cambridge, Mass., pp. 21-31.

Cartwright, R. (1987b). Propositions of pure logic, Philosophical Essays, Cambridge, Mass., pp. 217-236.

David, M. (1994). Correspondence and Disquotation, Oxford.

David, M. (2005). Künne on conceptions of truth, Grazer Philosophische Studien 70: 179-91.

Davidson, D. (1996). The folly of trying to define truth, Journal of Philosophy 93: $263-278$.

Davies, M. (1981). Meaning, Quantification, Necessity, London.

Dodd, J. (2000). An Identity Theory of Truth, London.

Dudman, V. (1976). Bedeutung for predicates, Studien zu Frege, III, Stuttgart, pp. 71-84.

Dummett, M. (1973). Frege - Philosophy of Language [FPL], London.

Dummett, M. (1991). The Logical Basis of Metaphysics [LBM], Cambridge, Mass.

Dummett, M. (1993a). Realism, The Seas of Language, Oxford, pp. 230-276.

Dummett, M. (1993b). The source of the concept of truth, The Seas of Language, Oxford, pp. 188-201. 
Dummett, M. (1993c). What is a theory of meaning? (II) [Meaning], The Seas of Language, Oxford, pp. 34-93.

Evans, G. (1982). Semantic structure and logical form, Collected Papers, Oxford, pp. 49-75.

Field, H. (2001). Disquotational truth and factually defective discourse, Truth and the Absence of Fact, Oxford, pp. 222-258.

Forbes, G. (1986). Truth, correspondence and redundancy, in G. Macdonald and C. Wright (eds), Fact, Science and Morality, Oxford, pp. 27-54.

Frege, G. (1967a). Über Begriff und Gegenstand, Kleine Schriften, Hildesheim, pp. 192-205.

Frege, G. (1967b). Über die Grundlagen der Geometrie, Kleine Schriften, Hildesheim, p. $262 \mathrm{ff}$.

Frege, G. (1967c). Funktion und Begriff, Kleine Schriften, Hildesheim, pp. 125-142.

Frege, G. (1976). Brief an Paul Linke, Wissenschaftlicher Briefwechsel [WB], Hamburg, pp. 153-156. Trans. as Philosophical and Mathematical Correspondence. Oxford 1979.

Frege, G. (1986). Die Grundlagen der Arithmetik, Hamburg. Trans. as The Foundations of Arithmetic. Oxford 1950.

Geach, P. (1951). On what there is, Proceedings of the Aristotelian Society SV 25: $137-148$.

Gómez-Torrente, M. (2005). Künne, W. - Conceptions of Truth, Philosophical Quarterly 55: 371-373.

Grover, D., Camp, J. and Belnap, N. (1992). A prosentential theory of truth, A Prosentential Theory of Truth, Princeton, pp. 70-120.

Gupta, A. (1998). Tarski's definition of truth, in E. Craig (ed.), Routledge Encyclopedia of Philosophy, London.

Gupta, A. (2002). An argument against Tarski's Convention T, in R. Schantz (ed.), What is Truth, Berlin, pp. 225-237.

Hofweber, T. (2006). Wolfgang Künne, Conceptions of Truth, Philosophical Review 114: 136-139.

Horwich, P. (1998). Truth, 2 edn, Blackwell, Oxford.

Horwich, P. (2001). A defense of minimalism [Defense], in M. Lynch (ed.), The Nature of Truth, Cambridge, Mass., pp. 559-577.

Horwich, P. (2003). A minimalist critique of Tarski on truth, in J. Hintikka, T. Czarnecki, K. Kijania-Placek, T. Placek and A. Rojszczak (eds), Philos- 
ophy and Logic: In Search of the Polish Tradition, Dordrecht, pp. 3-12.

Kahn, C. (1973). The Verb 'be' in Ancient Greek, Dordrecht.

Keil, G. (2005). Wahrheiten, die niemand kennen kann. Zu Wolfgang Künnes Verteidigung des alethischen Realismus, Zeitschrift für philosophische Forschung 59: 404-415.

Kirkham, R. (1992). Theories of Truth [ThT], Cambridge, Mass.

Künne, W. (2003). Conceptions of Truth [CT], Oxford.

Künne, W. (2007). Abstrakte Gegenstände, Frankfurt/M.

Kripke, S. (1976). Is there a problem about substitutional quantification?, in G. Evans and J. McDowell (eds), Truth and Meaning, Oxford, pp. 325-419.

Leibniz, G. (1962). Nouveaux essais sur l'entendement humain, Sämtliche Schriften und Briefe, Vol. A VI, 6, Berlin. Trans. as New Essays on Human Understanding. Cambridge 1996.

Mackie, J. (1973). Truth, Probability, and Paradox, Oxford.

Marconi, D. (2006). Conceptions of Truth, by Wolfgang Künne, European Journal of Philosophy 14: 138-146.

Moore, G. E. (1953). Some Main Problems in Philosophy [SMPP], London.

Ockham, W. (1974-1988). Opera Philosophia, New York.

Patterson, D. (2005). Sentential truth, denominalization, and the liar: Aspects of the modest account of truth, Dialogue 44: 527-538.

Prior, A. N. (1967). Correspondence theory of truth, in P. Edwards (ed.), The Encyclopedia of Philosophy, Vol. 2, London, pp. 223-232.

Prior, A. N. (1971). Objects of Thought [OT], Oxford.

Prior, A. N. (1976). The Doctrine of Propositions and Terms, London.

Quine, W. V. O. (1951). Mathematical Logic, revd edn, Cambridge, Mass.

Quine, W. V. O. (1960). Word and Object [WઐO], Cambridge, Mass.

Quine, W. V. O. (1961). Logic and the reification of universals, From a Logical Point of View, 2 edn, New York, pp. 102-129.

Quine, W. V. O. (1969). Existence and quantification, Ontological Relativity and Other Essays, New York, pp. 91-113.

Quine, W. V. O. (1970). Philosophy of Logic [PL], Englewood Cliffs.

Quine, W. V. O. (1974). Methods of Logic, 3 edn, London.

Quine, W. V. O. (1976). A logistical approach to the ontological problem, The Ways of Paradox and Other Essays, revd \& enlarged edn, Cambridge, Mass., pp. 197-202. 
Rami, A. (2005). Wolfgang Künne: Conceptions of Truth, Internationale Zeitschrift für Philosophie 14: 205-212.

Ramsey, F. P. (1991). On Truth, Dordrecht.

Rayo, A. and Yablo, S. (2001). Nominalism through de-nominalization, Noûs 35: 74-92.

Rosefeldt, T. (2003). Sein, Seiendes, Seiendheit. Eine These Heideggers aus der Sicht der analytischen Ontologie, Internationale Zeitschrift für Philosophie Heft 2: 99-121.

Rosefeldt, T. (2005). Wolfgang Künne: Conceptions of Truth, Philosophische Rundschau 52: 85-89.

Rundle, B. (1979). Grammar in Philosophy, Oxford.

Russell, B. (1964). The Principles of Mathematics, London.

Russell, B. (1966). Transatlantic "truth", Philosophical Essays, London, pp. 112-130.

Sainsbury, R. (2001). Logical Forms: An Introduction to Philosophical Logic, 2 edn, Oxford.

Sellars, W. (1963). Grammar and existence, Science, Perception and Reality, London, pp. 247-281.

Sellars, W. (1974). On the introduction of abstract entities, Essays in Philosophy and Its History, Dordrecht, pp. 287-317.

Simons, P. (1997). Higher-order quantification and ontological commitment, Dialectica 51: 255-271.

Soames, S. (1999). Understanding Truth, Oxford.

Strawson, P. F. (1959). Individuals, London.

Strawson, P. F. (1971a). A problem about truth, Logico-Linguistic-Papers, London, pp. 214-233.

Strawson, P. F. (1971b). Singular terms and predicates, Logico-LinguisticPapers, London, pp. 53-74.

Strawson, P. F. (1971c). Truth, Logico-Linguistic-Papers, London, pp. 190-213.

Strawson, P. F. (1974a). Freedom and Resentment and Other Essays, London.

Strawson, P. F. (1974b). Subject and Predicate in Logic and Grammar, London.

Strawson, P. F. (1976). Knowledge and truth, Indian Philosophical Quarterly 3: $273-282$.

Strawson, P. F. (1980). Reply to Grover, Philosophia (Israel) 10: 325-326.

Strawson, P. F. (1990). Two conceptions of philosophy, in R. Barrett and 
R. Gibson (eds), Perspectives on Quine, Oxford, pp. 310-318.

Strawson, P. F. (1992). Analysis and Metaphysics, Oxford.

Strawson, P. F. (1994). Individuals, in G. Fløistad (ed.), Philosophical Problems Today, I, Dordrecht, pp. 21-44.

Strawson, P. F. (1997). Concepts and properties, Entity and Identity, and Other Essays, Oxford, pp. 85-91.

Tarski, A. (1933). The concept of truth in formalized languages, Collected Papers, Basel-Boston-Stuttgart, pp. 51-198. quoted by original pagination of the separatum (Lwów 1935).

Twardowski, K. (1999). On so-called relative truths, On Actions, Products and Other Topics in Philosophy, Amsterdam, pp. 147-169.

van Cleve, J. (1994). Predication qithout universals?, Philosophy and Phenomenological Research 54: 577-590.

van Inwagen (2002). Generalizations of homophonic truth-sentences, in R. Schantz (ed.), What is Truth?, Berlin, pp. 205-222.

Whately, R. (1826). Elements of Logic.

Wiggins, D. (1984). The sense and reference of predicates: A running repair to Frege's doctrine and a plea for the copula, Philosophical Quarterly 34: $311-328$.

Williamson, T. (1999). Truthmakers and the converse barcan formula, $\mathrm{Di}$ alectica 53: 253-270.

Wittgenstein, L. (1967). Philosophische Untersuchungen / Philosophical Investigations, 3 edn, Oxford.

Wittgenstein, L. (1974). Philosophical Grammar, Oxford.

Wright, C. (1992). Truth and Objectivity [T®O], Cambridge, Mass. 